\title{
Effect of Adding Limestone on the Metallurgical Properties of Iron Ore Pellets
}

Mikko Iljana $^{\mathrm{a}, *}$, Antti Kemppainen ${ }^{\mathrm{a}}$, Timo Paananen ${ }^{\mathrm{b}}$, Olli Mattila ${ }^{\mathrm{b}}$, Erkki Pisilä ${ }^{\mathrm{b}}$, Mikhail Kondrakov $^{c}$, Timo Fabritius ${ }^{\text {a }}$

${ }^{a}$ Research Group of Process Metallurgy, University of Oulu, Finland

${ }^{\mathrm{b}}$ SSAB Europe, Raahe Works, Finland

${ }^{\mathrm{c}}$ Karelsky Okatysh, Severstal Resources, Kostomuksha, Russia

* Corresponding author at: Research Group of Process Metallurgy, University of Oulu, PO Box 4300, FI-90014 University of Oulu, Finland. Tel.: +358 294482556 (mobile).

E-mail-address: mikko.iljana@oulu.fi (Mikko Iljana). 


\section{Synopsis}

In order to produce high-quality pellets with good reducibility and superior softening and melting properties, certain additives are important. One of the most common fluxing materials for iron ore pellet production is limestone, which is mainly calcium oxide $(\mathrm{CaO})$. In this study, the effect of adding limestone on the metallurgical properties (reducibility, swelling, cracking, softening temperature, Low-Temperature Disintegration, Cold Crushing Strength) of acid iron ore pellets was investigated using a comprehensive set of metallurgical laboratory tests.

The dynamic reducibility test under unconstrained conditions showed a higher final degree of reduction in limestone-fluxed pellets compared to non-fluxed ones. Also in the reduction-softening test under load, the fluxed pellets reduced to a higher final degree of reduction, although they started to soften at a somewhat lower temperature. Swelling and cracking of the pellets during dynamic reduction was slightly increased by the addition of limestone, but not remarkably. Adding limestone slightly decreased the Cold Crushing Strength and increased the formation of fines in the hematite to magnetite reduction stage in the LTD test. However, all four parameters (CCS, LTD, swelling, and cracking) are within the acceptable range for blast furnace use.

KEY WORDS: Limestone; Iron ore pellets; Reduction under Load; Swelling; Low-Temperature Disintegration; Cold Crushing Strength 


\section{Introduction}

In general, the main types of pellets for the purposes of making iron are acid, basic and fluxed. In order to produce high-quality pellets, certain additives are important. The most common fluxing materials for iron ore pellet production are limestone $\left(\mathrm{CaCO}_{3}\right)$, dolomite $\left(\mathrm{Ca}, \mathrm{Mg}\left(\mathrm{CO}_{3}\right)_{2}\right)$ and olivine $\left(\mathrm{Mg}_{2} \mathrm{SiO}_{4}\right)$, but sometimes magnesite $\left(\mathrm{MgCO}_{3}\right)$ is also used. Fluxing agents are used not only to enhance slag formation, but also to improve softening and melting properties and to increase the reducibility of the burden materials before softening (Dwarapudi et al., 2012; Nogueira and Fruehan, 2003; Umadevi et al., 2011). In this study, the focus was placed on limestone as an additive in the production of iron ore pellets and its effect on pellet properties.

Some researchers have already studied the effect of basicity on the properties of iron ore pellets. One example is Umadevi et al. (2011), who carried out basket trials with iron ore pellets with basicity ranging from 0.08 to 1.15 in order to understand the effect of adding limestone on the microstructural, physical and metallurgical properties of iron ore pellets. In their study, the Tumble Index (TI) and the Cold Crushing Strength (CCS) increased with the increase in pellet basicity, while the Reduction Degradation Index (RDI) initially decreased, and then increased again with the increase in pellet basicity. The optimal value for blast furnace performance was a basicity of 0.33 . In the study by Loo and Bristow (1998a), high-basicity pellets showed higher reducibility and lower degradation than other pellets.

There are a variety of standard tests for characterizing the metallurgical properties of iron ore materials for blast furnace use. ISO 7215:2007 specifies a method to provide a relative measure for evaluating the extent to which oxygen can be removed from iron ores when reduced under the 
conditions prevailing in the reduction zone of a blast furnace. The test portion of $500 \mathrm{~g}$ is isothermally reduced in a fixed bed at $900{ }^{\circ} \mathrm{C}$ in CO- $\mathrm{N}_{2}$ gas for 180 minutes. The degree of reduction is calculated from the oxygen mass loss after 180 minutes.

Swelling of the pellets occurs simultaneously with reduction and is common in the operation of the blast furnace. ISO 4698:2007 provides a standard for measuring the free-swelling index when pellets are reduced in an unconstrained bed under conditions resembling those in the reduction zone of a blast furnace. The test involves heating 18 pellets in a size range of $10-12.5 \mathrm{~mm}$ to $900{ }^{\circ} \mathrm{C}$ and reducing them isothermally for 60 minutes using a reducing gas consisting of $30 \mathrm{vol} \% \mathrm{CO}$ and 70 vol $\% \mathrm{~N}_{2}$ with a total volume flow rate of $15 \mathrm{l} / \mathrm{min}$. The average increase in volume is an indicator of the amount of swelling.

Due to the increased porosity of pellets, normal swelling can be advantageous for the reduction process (Singh and Björkman, 2004), while abnormal swelling detracts from the mechanical properties of the pellets, thus increasing the generation of dust and fines, which lowers the permeability of the pellet bed and makes operating problems more likely to occur (Bahgat et al., 2009). The degree of size degradation of iron ores in the low-temperature reduction zone of a blast furnace can be evaluated according to the ISO 13930:2007 standard test, which is carried out isothermally at $500{ }^{\circ} \mathrm{C}$ in a gas atmosphere consisting of $20.0 \mathrm{vol} \% \mathrm{CO}, 20.0 \mathrm{vol} \% \mathrm{CO}_{2}, 2.0 \mathrm{vol} \%$ $\mathrm{H}_{2}$ and 58.0 vol\% $\mathrm{N}_{2}$ with a total gas volume flow rate of $201 / \mathrm{min}$. The standard test gives a relative measure for evaluating the disintegration of the iron burden materials when hematite is reduced to magnetite, namely the percentage of the $+6.3 \mathrm{~mm}$ fraction after reduction (Loo and Bristow, 1998b). 
ISO 4700:2007 specifies a method for measuring the compressive load required to cause breakage of pellets. The CCS test indicates the ability of pellets to withstand both the load during storage and handling and the load of burden material in the blast furnace. In the test, a single pellet in a size range of 10.0-12.5 $\mathrm{mm}$ is compressed at a specific speed. One test portion comprises at least 60 pellets selected randomly from the test sample. The compression is repeated for all pellets in the test portion. The Cold Crushing Strength is calculated as the arithmetic mean of all the measurements obtained. According to the standard, the standard deviation of the measurements must also be presented. An acceptable level for the CCS value of the pellets used in the blast furnace varies in literature from 150 daN (Geerdes et al., 2009) to 200-230 daN (Dwarapudi et al., 2010, 2011, 2012). Furthermore, Geerdes et al. (2009) point out that a little lower average compression strength has no drawback for the blast furnace process as long as it is not caused by an increased percentage of very weak pellets $(<60 \mathrm{daN})$.

It is generally known that in shaft furnaces iron-bearing materials are exposed to increasing temperature and mechanical load under reducing conditions. Due to mechanical stress caused by upper layers, iron-bearing material layers contract and finally collapse during melting. The behaviour of iron-bearing materials during contraction and melting is dependent on the chemistry and structure of the burden material and on reducing conditions, i.e. temperature, mechanical load, reducing gas composition, etc. (Sterneland and Lahiri, 1999).

In shaft furnaces, it is desirable that the burden holds a lumpy packed structure to as high a temperature as possible, and that the temperature range of the start of softening to melting (known as the cohesive zone) is as narrow as possible (Matsui et al., 2003). ISO 7992:2007 is a standardised Reduction under Load (RUL) test which provides a relative measure for evaluating the structural 
stability of iron ores when reduced under the conditions prevailing in the reduction zone of a blast furnace. A test portion weighing $1200 \mathrm{~g}$ is isothermally reduced in a fixed bed in a tube made of heat-resistant steel at $1050{ }^{\circ} \mathrm{C}$ under a static load in a CO- $\mathrm{H}_{2}-\mathrm{N}_{2}$ gas atmosphere until a reduction degree of $80 \%$ is obtained. As a result, the reduction curve is obtained, the differential pressure at $80 \%$ reduction is calculated, and the change in the height of the test bed at $80 \%$ reduction is measured. Because of the relatively low test temperature, liquid phases do not form when using traditional iron-bearing materials and the focus is only on the reduction of iron oxides under mechanical and chemical stress.

Sterneland et al. (2003) found the softening and melting behaviour to be the same in the RUL laboratory test as in the experimental blast furnace (EBF) located in Luleå. However, the progress of reduction down through the burden of the experimental blast furnace was similar, but not identical, to the results of the RUL experiments. Thereby, they concluded that the experimental conditions must be carefully chosen in order to be able to simulate reduction, softening and melting with laboratory experiments. Thus, in this paper, dynamic gas composition - temperature profiles simulating blast furnace conditions have been preferred to standard isothermal tests to study the effect of adding limestone on the metallurgical properties of iron ore pellets. 


\section{Materials}

Acid iron ore pellets with $4.6 \mathrm{wt} \% \mathrm{SiO}_{2}$ manufactured by Severstal Resources in Karelia were used in the investigations. Both test pellets were produced in a laboratory-scale pelletizing drum and fired in sample baskets set in the middle of the sintering belt on the same production line as commercial blast furnace pellets. One set of pellets was fluxed slightly with limestone $\left(\mathrm{CaCO}_{3}\right)$ and was labelled "non-fluxed", while the other one was highly limestone-fluxed and was labelled "fluxed". The $\mathrm{CaO}$ content of the pellets was $0.51 \mathrm{wt} \%$ and $3.20 \mathrm{wt} \%$, respectively. Chemical analyses of the pellets are presented in Table 1. The contents of $\mathrm{CaO}, \mathrm{MgO}, \mathrm{Al}_{2} \mathrm{O}_{3}$ and $\mathrm{S}$ were measured by XRF and the $\mathrm{SiO}_{2}$ content by a gravimetric method. Furthermore, the total iron content $\left(\mathrm{Fe}_{\text {tot }}\right)$ and the oxidation stage of the iron were measured by a titration method, and the content of alkaline components $\left(\mathrm{K}_{2} \mathrm{O}\right.$ and $\left.\mathrm{Na}_{2} \mathrm{O}\right)$ by FAAS. The total iron content of the fluxed pellets was slightly lower than that of the non-fluxed pellets due to the higher amount of flux. The divalent iron (FeO) content of the non-fluxed and fluxed pellets was $0.2 \mathrm{wt} \%$ and $0.6 \mathrm{wt} \%$, respectively. The higher divalent iron content in the fluxed pellets corresponds to a higher proportion of magnetite in the pellets and is an indicator of the sintering conditions. The size distribution of the pellets was quite similar (see the results of the sieve analysis in Figure 1). Most of the pellets were in the $10.0-12.5 \mathrm{~mm}$ size fraction.

Table 1, Figure 1

The photomicrographs showing the internal structure of the pellet core in the fired non-fluxed and the fluxed iron ore pellets are shown in Figure 2. The microstructure has been photographed with FESEM (Zeiss Ultra Plus) and the phases were identified by FESEM with an EDS detector. In the fluxed pellets, there are more macro-pores and fewer micro-pores compared to the non-fluxed pellets. A high amount of quartz grains can be observed in the both pellet grades. Additionally, 
some decomposed carbonate grains are detectable in the fired fluxed pellets.

Figure 2 


\section{Research methods}

\subsection{Reducibility}

The reducibility of the pellets under free conditions was tested with a high-temperature furnace named BFS (Blast Furnace gas phase Simulator). The operational description of the BFS is presented in an earlier paper (Iljana et al., 2012). The reducibility test carried out here is not a standard test because the ISO 7215 reducibility test is carried out under isothermal conditions and in a static gas atmosphere, but the conditions in the blast furnace process are actually dynamic. Prior to the experiment, the pellets were magnetically classified into two groups depending on the size of the magnetite nucleus in order to eliminate the effect of the fluctuation in the firing conditions on the pellet properties. A detailed description of the sample preparation is given in the earlier paper (Iljana et al., 2012).

In the reducibility test, a loose-packed layer of 26 pellets having no magnetite nucleus or only a small one and a total weight of $120 \pm 0.2 \mathrm{~g}$ was placed in the high-temperature furnace in the sample basket. An initial sample size of $12.5-16 \mathrm{~mm}$ was used in order to eliminate the effect of particle size on the reducibility of the pellets. The degree of reduction was determined based on the weight change in the mass of the pellet batch, measured on laboratory scales before and after the experiment. In the calculations to judge the degree of reduction, the content of the total iron and the divalent iron were taken into account. Prior to the determination of the original weight of the pellets, the pellets were heat-treated at $110^{\circ} \mathrm{C}$ overnight to remove any moisture. The reduction conditions in the reducibility test were similar to the "No additives" reduction swelling test described in the following chapter. 


\subsection{Dynamic reduction swelling behaviour}

Three reduction swelling tests were carried out with the pellets. Magnetically classified pellets having no magnetite nucleus or only a small one, in a size range of $12.5-16 \mathrm{~mm}$, and being visually round-shaped with an initial weight of $4.5 \pm 0.2 \mathrm{~g}$ were used in the tests. In each reduction swelling experiment, two non-fluxed and two fluxed pellets were put into a sample basket. Each swelling experiment followed the same operation line in the Fe-O-CO- $\mathrm{CO}_{2}$ phase stability diagram presented in the earlier paper (Iljana et al., 2012). The operation line simulates the temperature and the $\mathrm{CO} / \mathrm{CO}_{2}$ ratio in the blast furnace shaft and is consistent with the general understanding of how CO- $\mathrm{CO}_{2}$ gas composition changes in the blast furnace shaft. The experiment carried out under the basic conditions in the $\mathrm{CO}-\mathrm{CO}_{2}-\mathrm{N}_{2}$ gas was labelled the "No additives" test and the conditions are shown in Figure 3. The basic atmosphere profile was modified with the addition of sulphur and potassium gas, the first one named the "Medium-S" test and the latter one the "High-K" test (see Figure 4). The total gas volume rate was $10 \mathrm{l} / \mathrm{min}$ in each reduction swelling experiment. Adjusting the partial pressure of sulphur and potassium in the reducing gas is introduced in the earlier paper (Iljana et al., 2013).

Figure 3, Figure 4

\subsection{Reduction-softening behaviour}

The softening behaviour of the pellets was studied with a high-temperature furnace named ARUL (Advanced Reduction under Load) shown in Figure 5. The ARUL test is a dynamic reduction and softening test for pellets, sinters and lump ores and has been developed at Rautaruukki for both research and quality control purposes to study high-temperature properties of iron-bearing burden materials (Hooey, 1999). The ARUL test should not be confused with the ISO 7992:2007 standardized RUL test. In the ARUL reduction-softening test, a loose-packed pellet layer with a 
height of $90 \mathrm{~mm}(10.0-12.5 \mathrm{~mm}$ in size) was put in a graphite cylinder (diameter $70 \mathrm{~mm}$ ) which has a perforated and movable bottom and lid. The pellet batch having a total weight of $650-700 \mathrm{~g}$ was simultaneously heated in a resistor furnace and continuously reduced with gases simulating blast furnace reduction conditions. The total gas volume flow rate was $20 \mathrm{l} / \mathrm{min}$. The compression force of $100 \mathrm{kPa}$ was started at $800{ }^{\circ} \mathrm{C}$ and lasted until the end of the test. The test ended and the cooling of the sample with nitrogen began when the pressure difference over the sample increased to 70 mbar. At that stage, the structure of the sample had become so dense that the reducing gases had major difficulties penetrating through the material layer simulating the cohesive zone in the blast furnace. During the test, the sample temperature inside the test burden, the pressure difference across the sample and the height of the test material burden were measured continuously.

Figure 5 The reduction-softening test was carried out with the MASSIM program in $\mathrm{CO}-\mathrm{CO}_{2}-\mathrm{N}_{2}$ gas under dynamic conditions similar to the "No additives" test used to study the reducibility and the basic reduction swelling behaviour, the only difference being at $1100{ }^{\circ} \mathrm{C}$, when in the reduction-softening test the temperature continued to increase until a gas-impermeable structure was formed, but the "No additives" test had an isotherm of 40 minutes at $1100{ }^{\circ} \mathrm{C}$ due to temperature limitations of the steel tube in the BFS furnace. The difference in the gas composition and in the temperature profile in the reduction-softening experiment has been marked with a dashed line in Figure 3. The reducing conditions are illustrated in a Fe-O-CO- $\mathrm{CO}_{2}$ phase stability diagram in Figure 6 drawn from the data in the HSC Chemistry 7.0 thermodynamic calculation software (Roine, 2009).

Figure 6 For characterization of the softening behaviour of the iron ore pellets, the following indices have been derived: The TDP20, TDP50 and TDP70 values state the temperature at pressure differences of 20 mbar, 50 mbar and 70 mbar, respectively. The TDP20 value has been chosen to indicate the 
onset of softening and the TDP70 value is the temperature when gases cannot penetrate through the material layer anymore and the test ends. $\mathrm{RD}_{\text {final }}$ is the reduction degree at the end of the test and is calculated based on weight change during the test and the total iron and divalent iron content. The weight change during the test is determined by measurements performed before and after the test with laboratory scales.

After the reduction-softening experiments, the test sample was sliced and polished (see Figure 7). The polished sections were studied with a Light Optical Microscope (Olympus BX51) and a Field Emission Scanning Electron Microscope (Zeiss Ultra Plus) with an EDS detector (Oxford Instruments). Before the EDS analyses the polished sections were coated with carbon to ensure electrical conductivity.

Figure 7

\subsection{Low-Temperature Disintegration and Cold Crushing Strength}

The amount of size degradation of iron ores in the low-temperature reduction zone of a blast furnace was evaluated according to the ISO 13930:2007 standard test, which is carried out isothermally at $500{ }^{\circ} \mathrm{C}$ in a gas atmosphere consisting of $20.0 \mathrm{vol} \% \mathrm{CO}, 20.0 \mathrm{vol} \% \mathrm{CO}_{2}, 2.0 \mathrm{vol} \%$ $\mathrm{H}_{2}$ and $58.0 \mathrm{vol} \% \mathrm{~N}_{2}$ with a total gas volume flow rate of $20 \mathrm{l} / \mathrm{min}$. The LTD sample consists of 500 g pellets in sizes of $10-12.5 \mathrm{~mm}$. The standard test gives a relative measure for evaluating the disintegration of the iron burden materials when hematite is reduced to magnetite, namely the percentage of the $+6.3 \mathrm{~mm}$ fraction after reduction. The LTD value indicates the tendency to generate fines during reduction in the upper part of the blast furnace shaft.

The amount of pellet breakage during storage and handling and charging the blast furnace was evaluated according to the CCS test. In the test, 50 pellets $(10-12.5 \mathrm{~mm})$ from each initial pellet 
sample were compressed using crushing strength test equipment. 


\section{Results}

A series of metallurgical tests were carried out on the pellets in order to find out the effect of adding limestone on the metallurgical properties of acid iron ore pellets.

\subsection{Reducibility}

In the "No additives" reducibility test carried out for a $120 \mathrm{~g}$ portion of pellets, the final degree of reduction for the non-fluxed and fluxed pellets was $59.4 \%$, and $63.5 \%$, respectively. The positive effect of limestone on the reducibility of acid iron ore pellets under simulated blast furnace shaft conditions was noticeable.

\subsection{Dynamic reduction swelling behaviour}

Pellet images after the swelling experiments are shown in Figure 8. The cracking of non-fluxed acid iron ore pellets was very limited. Generally, adding limestone led to increased cracking of pellets under reducing conditions containing sulphur and potassium. In $\mathrm{CO}-\mathrm{CO}_{2}-\mathrm{N}_{2}$ gas, neither of the pellet grades cracked.

Figure 8

The average reduction swelling indices and average degrees of reduction for the non-fluxed and fluxed pellet grades in each dynamic reduction swelling experiment are presented in Figure 9. The RSI value shows the volume change of the pellets; a positive RSI value indicates swelling, and negative value shrinkage. Limestone led to swelling of the pellets, but the amount of volume increase was limited. Sulphur in the reducing gas led to contraction of the pellets, and potassium in the reducing gas to a volume increase in the pellets. Furthermore, the positive effect of adding limestone on the final degree of reduction was noticed in each dynamic reduction swelling test. 


\subsection{Reduction-softening behaviour}

Images of the pellet samples after the reduction-softening test can be seen in Figure 10. The orientation in the image is similar to the orientation in the test device, thus the reducing gases have gone through the burden from bottom to top. In the top part of the sample, the pellets are somewhat flattened themselves due to the load showing a softened structure. At the end of the reductionsoftening experiment, melt has started to squeeze through the top holes in the graphite crucible.

Figure 10

The cross-sections of the samples after the reduction-softening test for the non-fluxed and fluxed pellets are shown in Figure 11. The orientation in the image is similar to the orientation in the test device. Light grey depicts metallic iron and dark grey wüstite. It can be seen that generally the lower part is better reduced than the upper part because of the descending reducing capability of gases from the bottom to the top of the sample. Partly reduced (=wüstite) areas are located practically at the core of pellets, indicating topochemical reduction from the periphery towards the core of individual pellets.

\section{Figure 11}

The numerical results of the reduction-softening tests are presented in Table 2. The degree of reduction after the reduction-softening experiment was $45.9 \%$ for the non-fluxed pellets and 50.2 $\%$ for the fluxed pellets. Softening began at a temperature $35{ }^{\circ} \mathrm{C}$ lower for fluxed pellets compared to non-fluxed pellets, but the test ended at a temperature only $10{ }^{\circ} \mathrm{C}$ lower. Thus, the softening zone was broader for the fluxed pellets. Furthermore, the final degree of reduction was higher for the fluxed pellets compared to the non-fluxed ones. The amount of compression during the test was $\operatorname{similar}(\sim 50 \%)$. 


\section{Table 2}

The pressure difference and compression curves in the reduction-softening test are shown in Figure 12 together with the measured sample temperature. The pressure difference across the sample indicates the ability of gases to penetrate through the pellet layer. The pressure difference curve is very sharp when softening occurred for the non-fluxed pellets. With the fluxed pellets, the pressure difference across the sample increased more slowly and occurred over a broader temperature range. Compression of the fluxed pellets began to intensify when softening.

Figure 12

\subsection{Low-Temperature Disintegration and Cold Crushing Strength}

The non-fluxed and fluxed pellets were tested according to the ISO 13930:2007 standard to study the disintegration of the pellets in the low-temperature reduction zone of a blast furnace. The LTD value, indicating the percentage of the $+6.3 \mathrm{~mm}$ fraction after stressing the pellet sample isothermally at $500{ }^{\circ} \mathrm{C}$ in a CO-CO $2-\mathrm{H}_{2}-\mathrm{N}_{2}$ atmosphere, was $89.1 \%$ for the non-fluxed pellets and $73.3 \%$ for the fluxed pellets. The average Cold Crushing Strength was $265.1 \mathrm{daN}$ and $213.7 \mathrm{daN}$, respectively, and the standard deviation of the measurements was $93.1 \mathrm{daN}$ for the non-fluxed pellets and 82.8 daN for the fluxed pellets. A CCS distribution curve is presented in Figure 13.

Figure 13 


\section{Discussion}

The principal effect of $\mathrm{CaO}$ is to form low melting calcium silicate compounds which act as a bonding agent for the iron oxides during sintering (Dwarapudi et al., 2011; Dwarapudi et al., 2014; Friel and Erickson, 1980). The amount of liquid formed in the sintering process of iron ore pellets must be high enough to bond the pellet, but not so much that the pellet core becomes too heavily sintered, pulling away from the shell and leading to cracking of pellets (Firth et al., 2008). In the fluxed pellets studied here, limestone has decomposed (see Figure 2 b.) and $\mathrm{CaO}$ has taken gaseous sulphur into a solid solution of $\mathrm{CaO}-\mathrm{CaS}$, ending up with a higher $\mathrm{S}$ content in the fluxed pellets compared to the non-fluxed ones. This was verified with FESEM-EDS analyses showing 29-31 wt $\% \mathrm{Ca}, 23-37 \mathrm{wt} \% \mathrm{O}, 24-26 \mathrm{wt} \% \mathrm{~S}$ and $\max 1 \mathrm{wt} \% \mathrm{Fe}$ in the decomposed carbonate grains. Sulphur originates from combustion of oil, which is used to produce heat in the sintering process. The sintering temperature was $1330 \pm 20{ }^{\circ} \mathrm{C}$ at the highest for both pellet grades.

A higher reducibility indicates more indirect reduction in the blast furnace, resulting in a lower coke rate and higher productivity. The reducibility test in $\mathrm{CO}-\mathrm{CO}_{2}-\mathrm{N}_{2}$ gas showed that limestone enhances the reduction reactions in the acid iron ore pellets. One reason for this is the higher porosity of the fluxed pellets compared to the non-fluxed ones. The porosity of the pellets was not measured; it estimated visually with a Light Optical Microscope (see Figure 2). The higher porosity in the fluxed pellets is due to the decomposition of limestone in the sintering process.

Limestone fluxed pellets are highly porous and therefore very reducible but physically weaker than non-fluxed ones. The CCS distribution (see Figure 13) is broad and the standard deviation is high for both pellet grades; therefore, the average CCS value alone is not a proper indicator of the 
mechanical properties of the pellets. Instead, the Cold Crushing Strength should preferably be estimated in regard to the acceptable level for blast furnace use, which varies in literature from 150 daN (Geerdes et al., 2009) to 200-230 daN (Dwarapudi et al., 2010, 2011, 2012). $88 \%$ of the nonfluxed pellets and $80 \%$ of the fluxed pellets had a CCS value of at least $150 \mathrm{daN}$. The amount of very weak pellets $(<60 \mathrm{daN})$ in the non-fluxed and fluxed pellets was $0 \%$ and $2 \%$. Concluding, the Cold Compression Strength of acid iron ore pellets decreases when limestone is added, but the pellets are still usable in blast furnaces.

The LTD test showed that more fines are generated in the hematite to magnetite reduction stage in the fluxed pellets compared to the non-fluxed pellets. The swelling tests showed somewhat increased cracking for the limestone fluxed pellets compared to the non-fluxed ones, which is in accordance with the results of the LTD test. One possible reason for increased cracking and fines formation is the higher divalent iron content in the fluxed pellets, because the earlier study by Iljana et al. (2012) indicates that the boundary between the original magnetite nucleus and the hematite shell acts as the source of cracks. Both measurements (CCS and LTD) suggest a slightly higher sintering temperature should be used for the fluxed pellets to bond the matrix more strongly together.

The volume change of the pellets was larger with the fluxed pellets compared to the non-fluxed ones in reduction. Nicolle and Rist (1979) have confirmed that $\mathrm{Ca}^{2+}$ ions promote whisker growth, ending up in swelling of the pellets. Wüstite takes lime into solid solution very rapidly and whiskers are formed as wüstite is reduced to metallic iron. In this study, the surface of the pellets showing the possible formation of whiskers was not studied. 
The liquid onset in the iron oxide core is one of the mechanisms that lead to the loss of mechanical strength in ferrous burden materials. The increase in pressure difference across the sample in the ARUL test is an indicator of the formation of liquid phases. The TDP20 value is an indicator of the temperature, at which the cohesive zone begins in a blast furnace and is an essential factor for process control. A high temperature, at which the gas-impermeable layer is formed, is favourable in the blast furnace process, as it provides more space for gaseous reduction (Sterneland et al., 2003). A high share of gaseous reduction leads to less $\mathrm{FeO}$ in the primary slag melt and to lower direct reduction rates, resulting in decreased coke consumption in the blast furnace process. In addition to high softening and melting temperatures, good high-temperature properties of iron-bearing burden materials can be specified as a narrow cohesive zone in the blast furnace (Borinder and Torssell, 1986).

Lower TDP values were measured for the fluxed pellets compared to the non-fluxed ones. Additionally, the pressure difference curve for the fluxed pellets was not as sharp as for the nonfluxed ones. Thus, when only one type of pellet is used in the blast furnace burden, the cohesive zone is higher in the vertical direction and is broader for the fluxed pellets compared to the nonfluxed ones. However, the degree of reduction in the area of the cohesive zone is higher for the fluxed pellets compared to the non-fluxed ones because of the positive effect of $\mathrm{CaO}$ on the reducibility under unconstrained conditions.

Borinder and Torssell (1986) state that a high melting point of slag and wüstite is more important than high reducibility, unless the melting of the metallic iron phase can be delayed. In order to clarify the difference in softening behaviour between the two types of iron ore pellets studied, the polished sections of the samples after the reduction-softening test were studied with LOM and 
FESEM-EDS. The composition of the slag phase between wüstite grains was the major area of interest.

The internal structure of the pellets after the reduction-softening test is shown in Figure 14. The photomicrographs have been taken with a Light Optical Microscope from the area of partly reduced iron oxides with wüstite as the main iron oxide. Light grey depicts wüstite, the dark grey around wüstite is inter-granular slag, the white colour is metallic iron, and the black parts are pores. Wüstite grains are round-shaped and they have grown considerably in size due to sintering. Furthermore, liquid slag has filled the micro-pores of the pellets and led to a coarse pore structure.

Figure 14

In the FESEM-EDS analyses of the pellets after the reduction-softening test, detectable phases were metallic iron, wüstite and inter-granular slag of olivine composition in both pellet grades. Wüstite and metallic iron had no impurities in either the non-fluxed or fluxed pellet samples. $\mathrm{CaO}$ is able to dissolve in the wüstite, which would decrease the solidus and liquidus temperatures, as can be seen in the $\mathrm{CaO}-\mathrm{FeO}_{n}$ phase diagram in contact with iron (Verein Deutscher Eisenhüttenleute, 1981). The melting point of pure wüstite is $1371{ }^{\circ} \mathrm{C}$ and because no impurities were dissolved in the wüstite and the reduction-softening experiments ended at a considerably lower temperature, the wüstite has been in a solid state until the end of the experiments. The composition of the intergranular slag differed between the two phases in being fayalite $\left(\mathrm{Fe}_{2} \mathrm{SiO}_{4}\right)$ in the non-fluxed pellets, and $\mathrm{Ca}-\mathrm{Fe}$ olivines in the fluxed pellets.

The reason for the formation of the gas-impermeable structure is apparently linked to the increase of inter-particle melt with olivine composition, allowing wüstite particles to move in relation to each other under mechanical stress. This can be seen clearly in Figure 15, which shows round 
wüstite grains lubricated by inter-granular slag. The composition of the phases analysed are shown in Table 3 for the non-fluxed pellets and in Table 4 for the fluxed ones. The difference in the slag composition and phase diagram examination may explain why the gas-impermeable structure formed at a somewhat lower temperature in the case of the fluxed pellets compared to the nonfluxed pellets.

Figure 15, Table 3, Table 4 In the non-fluxed pellets, approximately $2.1 \mathrm{wt} \% \mathrm{CaO}$ and $0.9 \mathrm{wt} \% \mathrm{MgO}$ were dissolved in the fayalite, corresponding to the mineralogical formula $\left(\mathrm{Fe}_{1.87} \mathrm{Ca}_{0.08} \mathrm{Mg}_{0.05}\right) \mathrm{SiO}_{4}$ (see Table 3). The minimum eutectic temperature for the $\mathrm{FeO}_{\mathrm{n}}-\mathrm{SiO}_{2}$ system in contact with iron is $1177^{\circ} \mathrm{C}$ in the composition section of $\mathrm{FeO}_{\mathrm{n}}-2 \mathrm{FeO} \cdot \mathrm{SiO}_{2}$ (Muan and Osborn, 1965; Verein Deutscher Eisenhüttenleute, 1981). The minimum eutectic temperature for the inter-granular slag in the nonfluxed pellets is even lower because of the $\mathrm{CaO}$ dissolved in the fayalite, but the amount of $\mathrm{FeO}-\mathrm{CaO}-\mathrm{SiO}_{2}$ eutectic liquid is very small because of the small amount of $\mathrm{CaO}$ in the non-fluxed pellets.

The average composition of the Ca-Fe olivines verified in the sample of the fluxed pellets after the reduction-softening test was $40.2 \mathrm{wt} \% \mathrm{FeO}, 32.0 \mathrm{wt} \% \mathrm{SiO}_{2}, 28.2 \mathrm{wt} \% \mathrm{CaO}$ and $0.5 \mathrm{wt} \% \mathrm{MgO}$, corresponding to the mineralogical formula $\left(\mathrm{Fe}_{1.04} \mathrm{Ca}_{0.94} \mathrm{Mg}_{0.02}\right) \mathrm{SiO}_{4}$ (see Table 4). The solidus for the inter-granular slag verified with FESEM-EDS is slightly over $1200^{\circ} \mathrm{C}$. When ignoring the small amount of $\mathrm{MgO}$, the $\mathrm{Ca}-\mathrm{Fe}$ olivines are located in the composition section of $2 \mathrm{CaO} \cdot \mathrm{SiO}_{2}$ $2 \mathrm{FeO} \cdot \mathrm{SiO}_{2}$ depicted in Figure 16 (Muan and Osborn, 1965; Verein Deutscher Eisenhüttenleute, 1981). For this system, the minimum eutectic temperature is $1115^{\circ} \mathrm{C}$, with a composition of $\left(\mathrm{Fe}_{1.6} \mathrm{Ca}_{0.4}\right) \mathrm{SiO}_{4}$. The eutectic temperature is in accordance with the TDP20 value attained in the reduction-softening experiment. Judging from this, it is obvious that primary slag with a 
composition near eutectic liquid has formed in the reduction-softening experiment and the composition of the primary slag has changed to contain less FeO due to reduction reactions proceeding during softening. Because no interrupted experiments were carried out, this hypothesis could not be verified. After the reduction-softening test, the cooling takes some time and during that the mineralogical composition of different phases can be affected. Because of continuous solubility in the system of $2 \mathrm{CaO} \cdot \mathrm{SiO}_{2}-2 \mathrm{FeO} \cdot \mathrm{SiO}_{2}, \mathrm{Ca}-\mathrm{Fe}$ olivines with different composition can be formed depending on which grains come into contact with each other. This explains the broader softening zone observed with the fluxed pellets compared to the non-fluxed ones.

Figure 16

The liquid onset occurred at somewhat lower temperatures than expected based on examining the phase stability diagram. This is due to the fluxing effect of alkaline components $\left(\mathrm{Na}_{2} \mathrm{O}\right.$ and $\left.\mathrm{K}_{2} \mathrm{O}\right)$. Although the amount of alkalis is very low (less than $0.2 \mathrm{wt} \%$ ), they can decrease the solidus temperature significantly, even though the fraction of liquid at this point is small (Nogueira and Fruehan, 2006).

The ARUL test was found to be an appropriate method to study the softening behaviour of iron ore pellets. It is a reduction and softening type, and should not be confused with the ISO 7992:2007 standardized RUL test. Actually, only slag phases and some iron in contact with the graphite crucible melt at least partially in the ARUL test.

Naturally, there are also some limitations in the ARUL test. In a real blast furnace, other slagforming elements are also captured by pellets, such as alkalis, sulphur and ash particles from metallurgical coke and alternative reducing agents. The effect of alkalis, sulphur and ash particles on inter-granular melt formation was not studied here, but problems may arise from the high 
sulphur load leading to partial melt formation of FeO-FeS at $915^{\circ} \mathrm{C}$ (Iljana et al., 2013; Verein Deutscher Eisenhüttenleute, 1981). Furthermore, this means that the numerical results of reductionsoftening experiments cannot be taken as a direct measure of the softening temperature of the ironbearing charge in a real blast furnace, but it shows the difference between different burden materials.

Additionally, in the reduction-softening test the gas-to-solid ratio was lower than in a real blast furnace due to experimental limitations. Another aspect to take into account is that both gases and solids were heated externally in the reduction-softening test, although heat transfer and oxygen transfer reactions in the blast furnace are interrelated (Biswas, 1981). Consequently, heat transfer in the furnace and its possible effect on the kinetics of the reduction of iron oxides cannot be accurately simulated. 


\section{Conclusions}

In this study, the effect of adding limestone on the metallurgical properties (reducibility, swelling, cracking, softening temperature, Low-Temperature Disintegration, Cold Crushing Strength) of acid iron ore pellets was investigated. The main implications drawn from the comprehensive set of metallurgical tests can be summarized as follows:

(1) Adding limestone increased the reducibility of the pellets by increasing the porosity of the pellets as the limestone decomposed in the sintering.

(2) Swelling and cracking of the pellets during dynamic reduction slightly increased when limestone was added.

(3) The final degree of reduction was higher in the reduction-softening test with the fluxed pellets compared to the non-fluxed ones, although softening began at a lower temperature with the fluxed pellets compared to the non-fluxed ones. The softening zone was broader with the fluxed pellets, indicating a broader cohesive zone in the blast furnace. In a blast furnace process, this means a cohesive zone located higher in the vertical direction when using fluxed pellets; this leads to a lower amount of direct reduction occurring in the blast furnace hearth, and thus decreased consumption of reducing agents.

(4) The reason for forming a gas-impermeable structure in the reduction-softening test is apparently linked to the increase of inter-particle melt allowing wüstite particles to move in relation to each other under mechanical stress. The inter-granular slag was composed of fayalite in the non-fluxed pellets and $\mathrm{Ca}-\mathrm{Fe}$ olivines in the fluxed pellets. $\mathrm{CaO}$ dissolved in fayalite decreases the solidus and liquidus temperature of the fluxed pellets because a lowmelting eutectic liquid can form.

(5) Adding limestone slightly decreased the Cold Crushing Strength of the acid pellets and 
increased the formation of fines in the hematite to magnetite reduction stage in the LTD test. However, the CCS and LTD values for the fluxed pellets are within the acceptable range for blast furnace use.

(6) The ARUL reduction-softening test was found to be appropriate for a comparative study between different iron ore pellet grades when reduction-softening behaviour is investigated. Additionally, it is an appropriate method to study the formation of slag phases under simulated blast furnace conditions. The ARUL test should not be confused with the ISO 7992:2007 standardized RUL test. 


\section{Abbreviations}

ARUL

BFS

CCS

$\mathrm{EBF}$

EDS

FAAS

FESEM

ISO

LOM

LTD

$\mathrm{RD}_{\text {final }}$

RDI

RSI

RUL

TDP20

TDP50

TDP70

TI

XRF
Advanced Reduction under Load

Blast Furnace gas phase Simulator

Cold Crushing Strength

Experimental Blast Furnace

Energy Dispersive Spectroscopy

Flame Atomic Absorption Spectrometry

Field Emission Scanning Electron Microscope

International Organization for Standardization

Light Optical Microscope

Low-Temperature Disintegration

Reduction Degree at the end of the reduction-softening test

Reduction Degradation Index

Reduction Swelling Index

Reduction under Load

Temperature at 20 mbar pressure drop in the reduction-softening test

Temperature at 50 mbar pressure drop in the reduction-softening test

Temperature at 70 mbar pressure drop in the reduction-softening test

Tumble Index

X-Ray Fluorescence 


\section{Acknowledgements}

This research is part of the Systems Integrated Metal Processes (SIMP) research programme coordinated by the Finnish Metals and Engineering Competence Cluster (FIMECC). Ruukki Metals Oy (at present a part of SSAB) and the Finnish Funding Agency for Technology and Innovation (TEKES) are acknowledged for funding this work. Severstal Resources are acknowledged for manufacturing the test pellets. The Center of Microscopy and Nanotechnology (CMNT) at the University of Oulu is acknowledged for providing mineralogical characterization services. $\mathrm{Mr}$ Tommi Kokkonen, a special laboratory technician at the University of Oulu, is acknowledged for his technical support. 


\section{References}

Bahgat, M., Abdel Halim, K.S., El-Kelesh, H.A., Nasr, M.I., 2009. Metallic iron whisker formation and growth during iron oxide reduction: K2O effect. Ironmaking Steelmaking 36 (5), 379-387.

Biswas, A.K., 1981. Principles of Blast Furnace Ironmaking: Theory and Practice. Cootha Publishing House, Brisbane.

Borinder, T., Torssell, K., 1986. High temperature behaviour of blast furnace pellets. Proc of ISSAIME 45th Ironmaking conference, Warrendale, PA, USA, pp. 13-18.

Dwarapudi, S., Banerjee, P.K., Chaudhary, P., Sinha, S., Chakraborty, U., Sekhar, C., Venugopalan, T., Venugopal, R., 2014. Effect of fluxing agents on the swelling behavior of hematite pellets. Int. J. Miner. Process. 126, 76-89.

Dwarapudi, S., Ghosh, T.K., Shankar, A., Tathavadkar, V., Bhattacharjee, D., Venugopal, R., 2010. Effect of pyroxenite flux on the quality and microstructure of hematite pellets. Int. J. Miner. Process. 96, 45-53.

Dwarapudi, S., Ghosh, T.K., Shankar, A., Tathavadkar, V., Bhattacharjee, D., Venugopal, R., 2011. Effect of pellet basicity and $\mathrm{MgO}$ content on the quality and microstructure of hematite pellets. Int. J. Miner. Process. 99, 43-53.

Dwarapudi, S., Ghosh, T.K., Tathavadkar, V., Denys, M.B., Bhattacharjee, D., Venugopal, R., 2012. Effect of $\mathrm{MgO}$ in the form of magnesite on the quality and microstructure of hematite pellets. Int. J. Miner. Process. 112-113, 55-62.

Firth, A.R., Garden, J.F., Douglas, J.D., 2008. Phase equilibria and slag formation in the magnetite core of fluxed iron ore pellets. ISIJ Int. 48 (11), 1485-1492.

Friel, J.J., Erickson, E.S., 1980. Chemistry, Microstructure, and Reduction Characteristics of Dolomite-Fluxed Magnetite Pellets. Metall. Trans. B 11 (2), 233-243.

Geerdes, M., Toxopeus, H., van der Vliet C., 2009. Modern Blast Furnace Ironmaking an introduction. IOS Press BV, Amsterdam, 164.

Hooey, P.L., 1999. Reduction and High Temperature Behaviour of Iron Ore Sinter Made from Magnetite Fines. PhD thesis, University of Oulu, Finland.

Iljana, M., Mattila, O., Alatarvas, T., Visuri, V., Kurikkala, J., Paananen, T., Fabritius, T., 2012. Dynamic and Isothermal Reduction Swelling Behaviour of Olivine and Acid Iron Ore Pellets under Simulated Blast Furnace Shaft Conditions. ISIJ Int. 52 (7), 1257-1265. 
Iljana, M., Mattila, O., Alatarvas, T., Kurikkala, J., Paananen, T., Fabritius, T., 2013. Effect of Circulating Elements on the Dynamic Reduction Swelling Behaviour of Olivine and Acid Iron Ore Pellets under Simulated Blast Furnace Shaft Conditions. ISIJ Int. 53 (3), 419-426.

ISO 13930, 2007. Iron ores for blast furnace feedstocks. Determination of low-temperature reduction-disintegration indices by dynamic method. ISO, Geneva.

ISO 4698, 2007. Iron ore pellets for blast furnace feedstocks. Determination of the free-swelling index. ISO, Geneva.

ISO 4700, 2007. Iron ore pellets for blast furnace and direct reduction feedstocks. Determination of the crushing strength. ISO, Geneva.

ISO 7215, 2007. Iron ores for blast furnace feedstocks. Determination of the reducibility by the final degree of reduction index. ISO, Geneva.

ISO 7992, 2007. Iron ores for blast furnace feedstocks. Determination of reduction under load. ISO, Geneva.

Loo, C.E., Bristow, N.J., 1998a. Properties of iron bearing materials under simulated blast furnace indirect reduction conditions: Part 3 Reducibility. Ironmaking Steelmaking 25 (5), 366-373.

Loo, C.E., Bristow, N.J., 1998b. Properties of iron bearing materials under simulated blast furnace indirect reduction conditions. Part 1 Review and experimental procedure. Ironmaking Steelmaking 25 (3), 222-232.

Matsui, Y., Sato, A., Oyama, T., Matsuo, T., Kitayama, S., Ono, R., 2003. All Pellets Operation in Kobe No. 3 Blast Furnace under Intensive Coal Injection. ISIJ Int. 43 (2), 166-174.

Muan, A., Osborn, E.F., 1965. Phase equilibria among oxides in steelmaking. Addison-Wesley Publishing Company Inc., Reading, Massachusetts.

Nicolle, R., Rist, A., 1979. The Mechanism of Whisker Growth in the Reduction of Wüstite. Metall. Trans. B 10, 429-438.

Nogueira, P.F., Fruehan, R.J., 2003. Blast furnace burden softening and melting phenomena Melting onset in acid and basic fluxed pellets. I\&SM 30 (7), 29-35.

Nogueira, P.F., Fruehan, R.J., 2006. Blast furnace burden softening and melting phenomena: Part III. Melt onset and initial microstructural transformations in pellets. Metall. Mat. Trans. B 37 (4), 551-558.

Roine, A., 2009. HSC Chemistry v. 7.00, Outotec Research Oy, Pori, Finland.

Singh, M., Björkman, B., 2004. Effect of Reduction Conditions on the Swelling Behaviour of Cement-bonded Briquettes. ISIJ Int. 44 (2), 294-303. 
Sterneland, J., Andersson, M.A.T., Jönsson, P.G., 2003. Comparison of iron ore reduction in experimental blast furnace and laboratory scale simulation of blast furnace process. Ironmaking Steelmaking 30 (4), 313-327.

Sterneland, J., Lahiri, A.K., 1999. Contraction and meltdown behaviour of olivine iron ore pellets under simulated blast furnace conditions. Ironmaking Steelmaking 26 (5), 339-348.

Umadevi, T., Kumar, P., Lobo, N.F., Prabhu, M., Mahapatra, P.C., Ranjan, M., 2011. Influence of Pellet Basicity $\left(\mathrm{CaO} / \mathrm{SiO}_{2}\right)$ on Iron Ore Pellet Properties and Microstructure. ISIJ Int. 51 (1), 14-20.

Verein Deutscher Eisenhüttenleute (ed), 1981. Slag atlas. Düsseldorf, Verlag Stahleisen m.b.H. 


\section{List of tables}

Table 1. Chemical composition of the pellets.

Table 2. Numerical results of the reduction-softening tests.

Table 3. Phase composition of the non-fluxed pellets (Figure 15 a.) after the reduction-softening test.

Table 4. Phase composition of the fluxed pellets (Figure 15 b.) after the reduction-softening test. 


\section{List of figures}

Figure 1. Size distribution of the pellets.

Figure 2. Backscattered electron images by FESEM from the core of (a) the non-fluxed and (b) the fluxed pellets.

Figure 3. Basic gas atmosphere and temperature profiles as a function of time in the reduction swelling and reduction-softening experiments (modified after Iljana et al., 2012, 2013).

Figure 4. Concentration of sulphur and potassium in the "Medium-S" and the "High-K" reduction swelling experiments (modified after Iljana et al., 2013).

Figure 5. Schematic diagram of the ARUL test device (modified after Hooey, 1999).

Figure 6. Reducing conditions in the reduction-softening test presented in a Fe-O-CO-CO $\mathrm{CO}_{2}$ phase stability diagram (modified after Iljana et al., 2012).

Figure 7. Sample preparation after the reduction-softening test.

Figure 8. Cracking of the pellets in the dynamic swelling tests.

Figure 9. Average reduction swelling indices (columns) and averages degrees of reduction (dots) in the reduction swelling experiments.

Figure 10. Digital camera images of the pellet samples after the reduction-softening test.

Figure 11. Digital camera images of the cross-sections of the samples after the reduction-softening test.

Figure 12. Compression and pressure difference curves in the reduction-softening test.

Figure 13. Cumulative distribution for the CCS values of the pellets.

Figure 14. LOM images from the core of (a) the non-fluxed and (b) the fluxed pellets after the reduction-softening test. 
Figure 15. Backscattered electron images by FESEM from the top area of the sample after the reduction-softening test in the polished sections of (a) the non-fluxed and (b) the fluxed pellets. Figure 16. Chemical composition of the inter-granular slag plotted to the composition section of $2 \mathrm{CaO} \cdot \mathrm{SiO}_{2}-2 \mathrm{FeO} \cdot \mathrm{SiO}_{2}$ (modified after Verein Deutscher Eisenhüttenleute, 1981). The black dot represents the non-fluxed pellets and the grey dot the fluxed ones. 
Table 1. Chemical composition of the pellets.

\begin{tabular}{ccc}
\hline Pellet grade & Non-fluxed & Fluxed \\
\hline Component & \multicolumn{2}{c}{ Content [wt\%] } \\
\hline $\mathrm{Fe}_{\text {tot }}$ & 65.6 & 63.8 \\
\hline $\mathrm{FeO}$ & 0.2 & 0.6 \\
\hline $\mathrm{CaO}$ & 0.51 & 3.20 \\
\hline $\mathrm{SiO}_{2}$ & 4.62 & 4.61 \\
\hline $\mathrm{MgO}$ & 0.15 & 0.18 \\
\hline $\mathrm{Al}_{2} \mathrm{O}_{3}$ & 0.38 & 0.34 \\
\hline $\mathrm{S}$ & 0.011 & 0.061 \\
\hline $\mathrm{K}_{2} \mathrm{O}$ & 0.109 & 0.100 \\
\hline $\mathrm{N}_{2} \mathrm{O}$ & 0.061 & 0.052 \\
\hline $\mathrm{CaO} / \mathrm{SiO}_{2}$ & 0.11 & 0.69 \\
\hline
\end{tabular}


Table 2. Numerical results of the reduction-softening tests.

\begin{tabular}{ccc}
\hline & Non-fluxed & Fluxed \\
\hline $\operatorname{TDP} 20\left[{ }^{\circ} \mathrm{C}\right]$ & 1122 & 1087 \\
\hline $\operatorname{TDP} 50\left[{ }^{\circ} \mathrm{C}\right]$ & 1137 & 1112 \\
\hline $\mathrm{TDP} 70\left[{ }^{\circ} \mathrm{C}\right]$ & 1140 & 1130 \\
\hline $\mathrm{TDP} 70-\mathrm{TDP} 20\left[{ }^{\circ} \mathrm{C}\right]$ & 18 & 43 \\
\hline Compression $[\%]$ & 48.4 & 50.5 \\
\hline $\mathrm{RD}_{\text {final }}[\%]$ & 45.9 & 50.2 \\
\hline
\end{tabular}


Table 3. Phase composition of the non-fluxed pellets (Figure 15 a.) after the reduction-softening test.

\begin{tabular}{ccccccc}
\hline No. & $\begin{array}{c}\mathbf{M g O} \\
{[\mathbf{w t} \% \mathbf{0}]}\end{array}$ & $\begin{array}{c}\mathbf{S i O}_{2} \\
{[\mathbf{w t} \%]}\end{array}$ & $\begin{array}{c}\mathbf{C a O} \\
{[\mathbf{w t} \%]}\end{array}$ & $\begin{array}{c}\mathbf{F e O} \\
{[\mathbf{w t} \%]}\end{array}$ & $\begin{array}{c}\text { Total } \\
{[\mathbf{w t} \%]}\end{array}$ & Formula \\
\hline 1 & 1.0 & 30.2 & 1.7 & 68.6 & 101.5 & \\
\hline 2 & 1.0 & 29.8 & 2.0 & 68.8 & 101.6 & \\
\hline 3 & 0.9 & 30.0 & 1.8 & 68.5 & 101.1 & \\
\hline 4 & 0.8 & 29.6 & 2.9 & 67.2 & 100.5 & \\
\hline Inter-granular slag (1-4) & 0.9 & 29.9 & 2.1 & 68.3 & 101.2 & $\left(\mathrm{Fe}_{1.87} \mathrm{Ca}_{0.08} \mathrm{Mg}_{0.05}\right) \mathrm{SiO}_{4}$ \\
\hline 5 & & & & 97.7 & 97.7 & \\
\hline 6 & & & & 98.2 & 98.2 & \\
\hline Wüstite (5-6) & & & & 137.5 & 137.5 & \\
\hline 7 & & & 136.5 & 136.5 & \\
\hline 8 & & & & & & \\
\hline Metallic iron (7-8) & & & & & \\
\hline
\end{tabular}


Table 4. Phase composition of the fluxed pellets (Figure 15 b.) after the reduction-softening test.

\begin{tabular}{ccccccc}
\hline No. & $\begin{array}{c}\mathbf{M g O} \\
{[\mathbf{w t \%}]}\end{array}$ & $\begin{array}{c}\mathbf{S i O}_{2} \\
{[\mathbf{w t} \%]}\end{array}$ & $\begin{array}{c}\mathbf{C a O} \\
{[\mathbf{w t} \%]}\end{array}$ & $\begin{array}{c}\mathbf{F e O} \\
{[\mathbf{w t} \%]}\end{array}$ & $\begin{array}{c}\text { Total } \\
{[\mathbf{w t} \%]}\end{array}$ & Formula \\
\hline 1 & 0.5 & 32.1 & 28.5 & 40.2 & 101.3 & \\
\hline 2 & 0.5 & 31.8 & 27.5 & 41.3 & 101.1 & \\
\hline 3 & 0.5 & 31.9 & 28.7 & 39.5 & 100.5 & \\
\hline 4 & 0.5 & 32.1 & 28.4 & 39.6 & 100.6 & \\
\hline Inter-granular slag (1-4) & 0.5 & 32.0 & 28.2 & 40.2 & 100.9 & $\left(\mathrm{Fe}_{1.04} \mathrm{Ca}_{0.94} \mathrm{Mg}_{0.02}\right) \mathrm{SiO}_{4}$ \\
\hline 5 & & & & 98.5 & 98.5 & \\
\hline 6 & & & & 97.6 & 97.6 & \\
\hline Wüstite (5-6) & & & & 98.0 & 98.0 & $\mathrm{FeO}$ \\
\hline 7 & & & & 136.1 & 136.1 & \\
\hline 8 & & & & 136.2 & 136.2 & \\
\hline Metallic iron (7-8) & & & & & \\
\hline
\end{tabular}




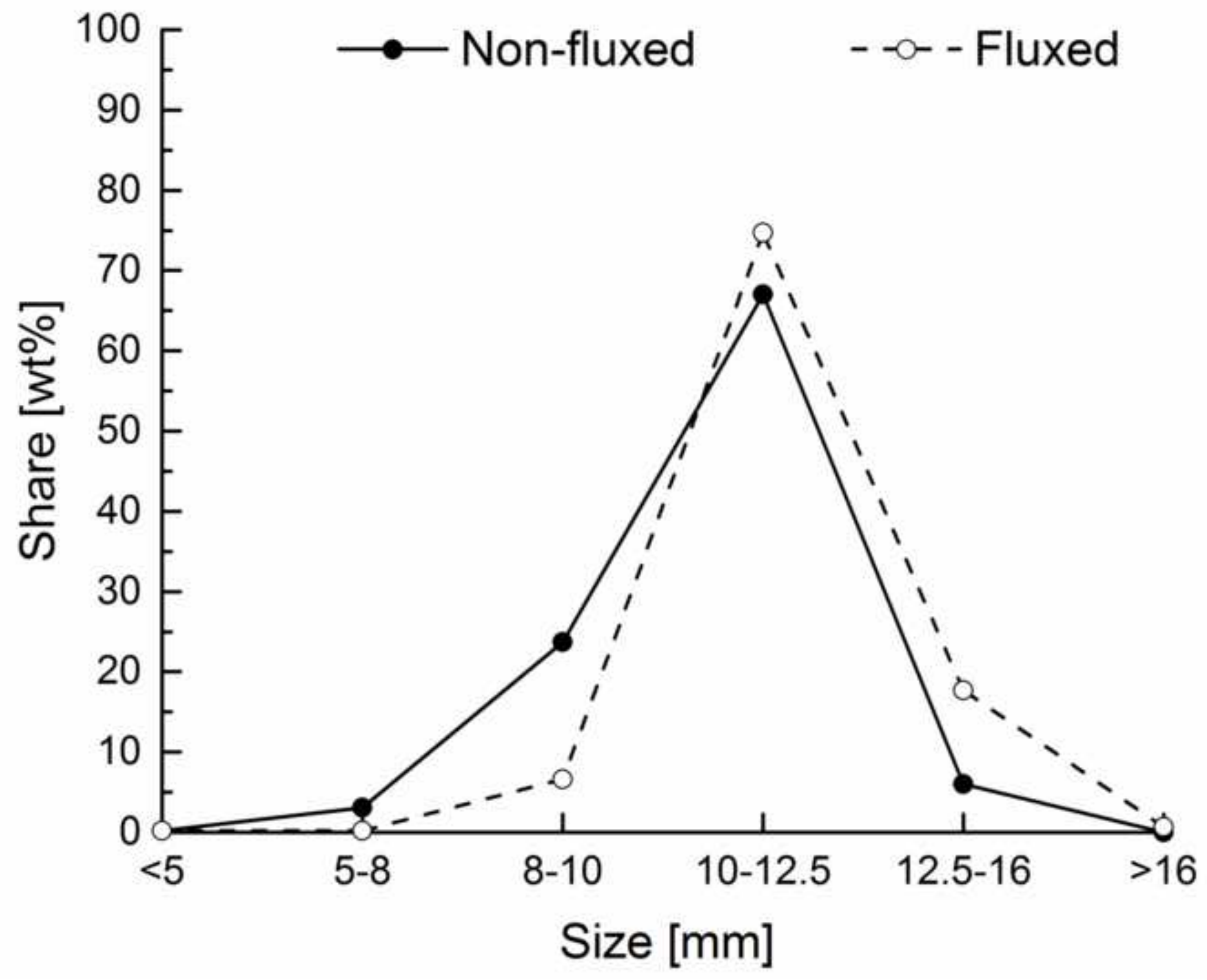


Click here to download high resolution image

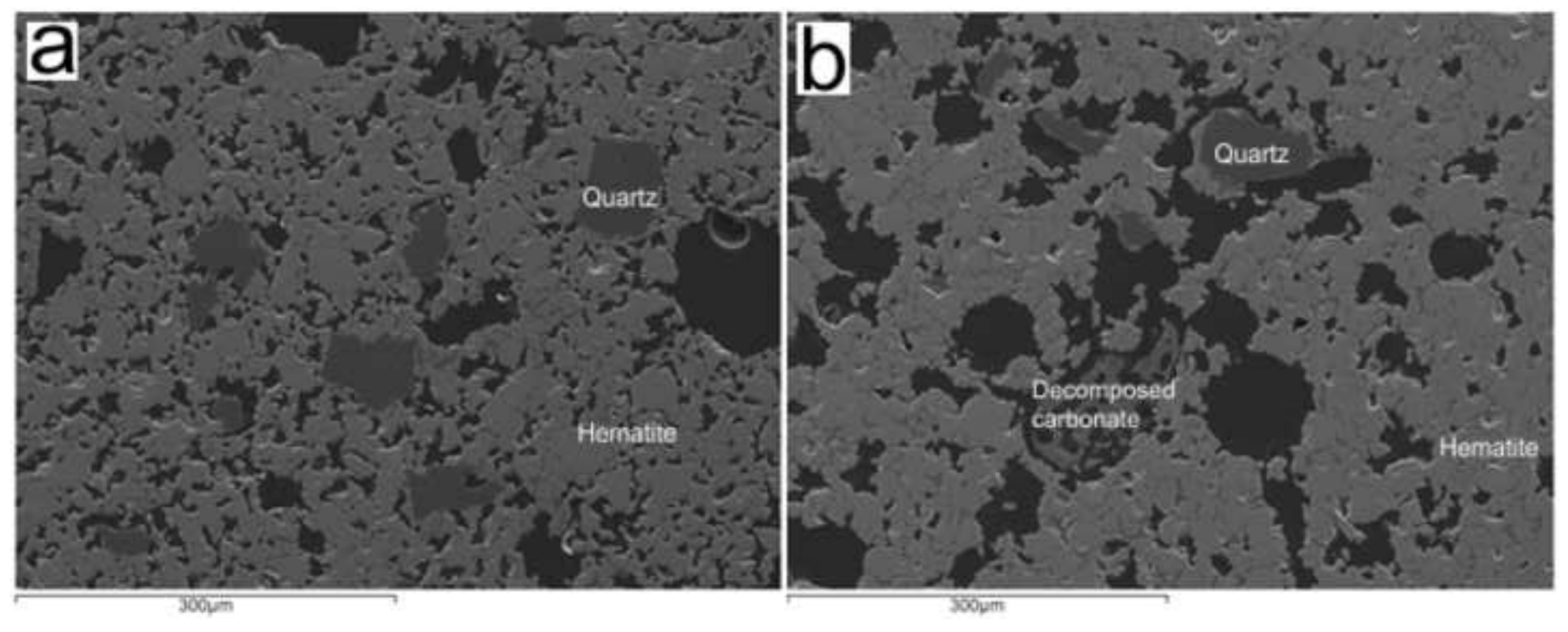

$300 \mathrm{~m}$

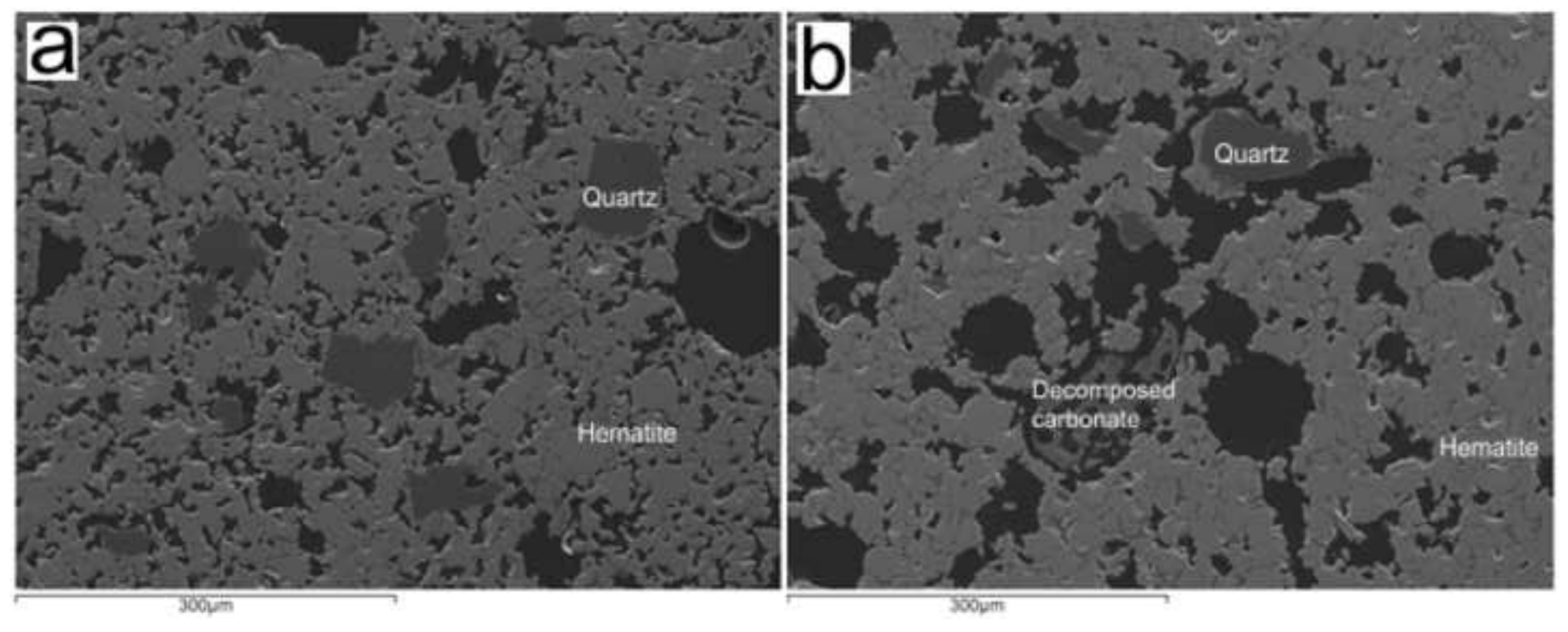

solom 


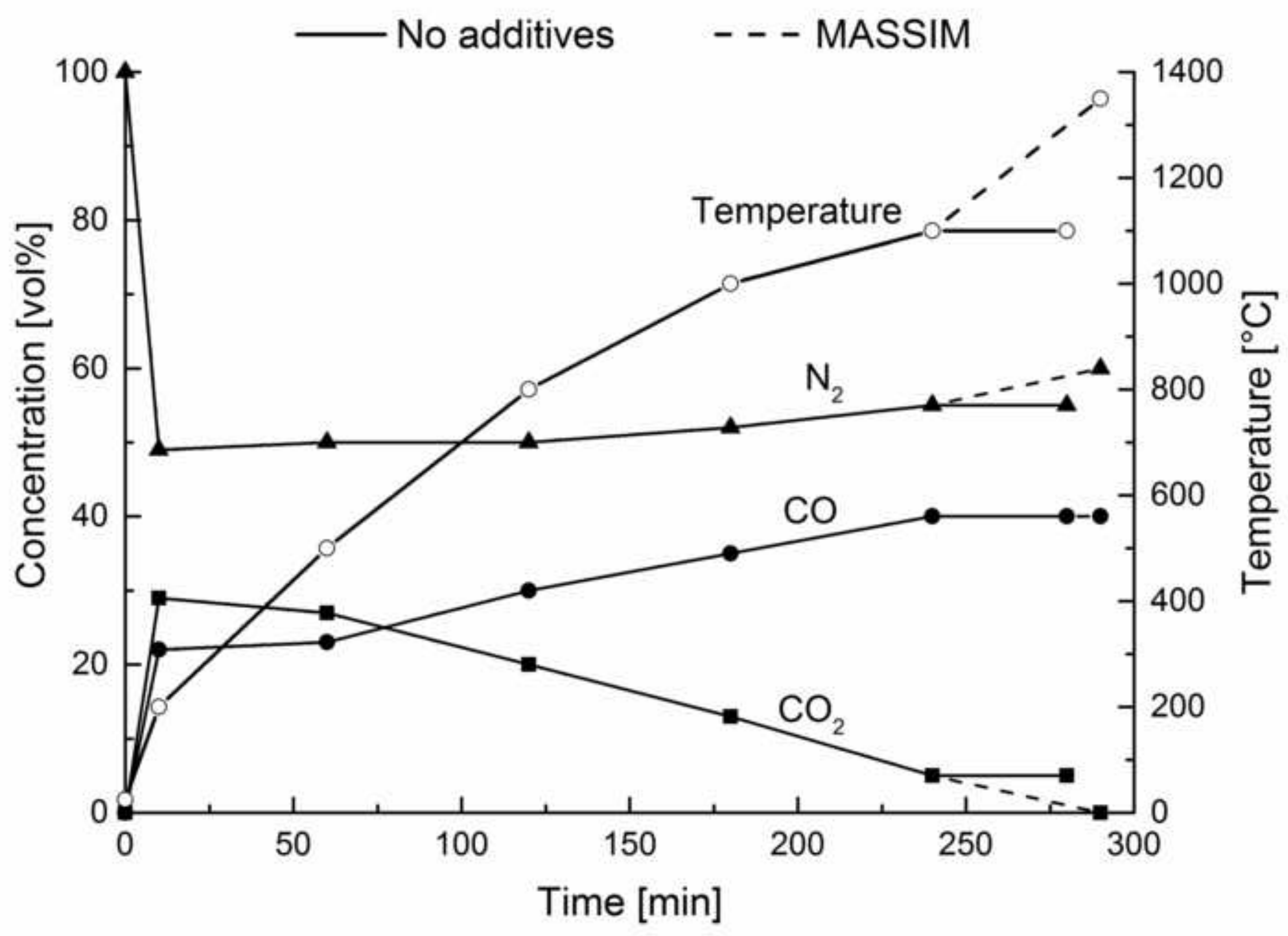




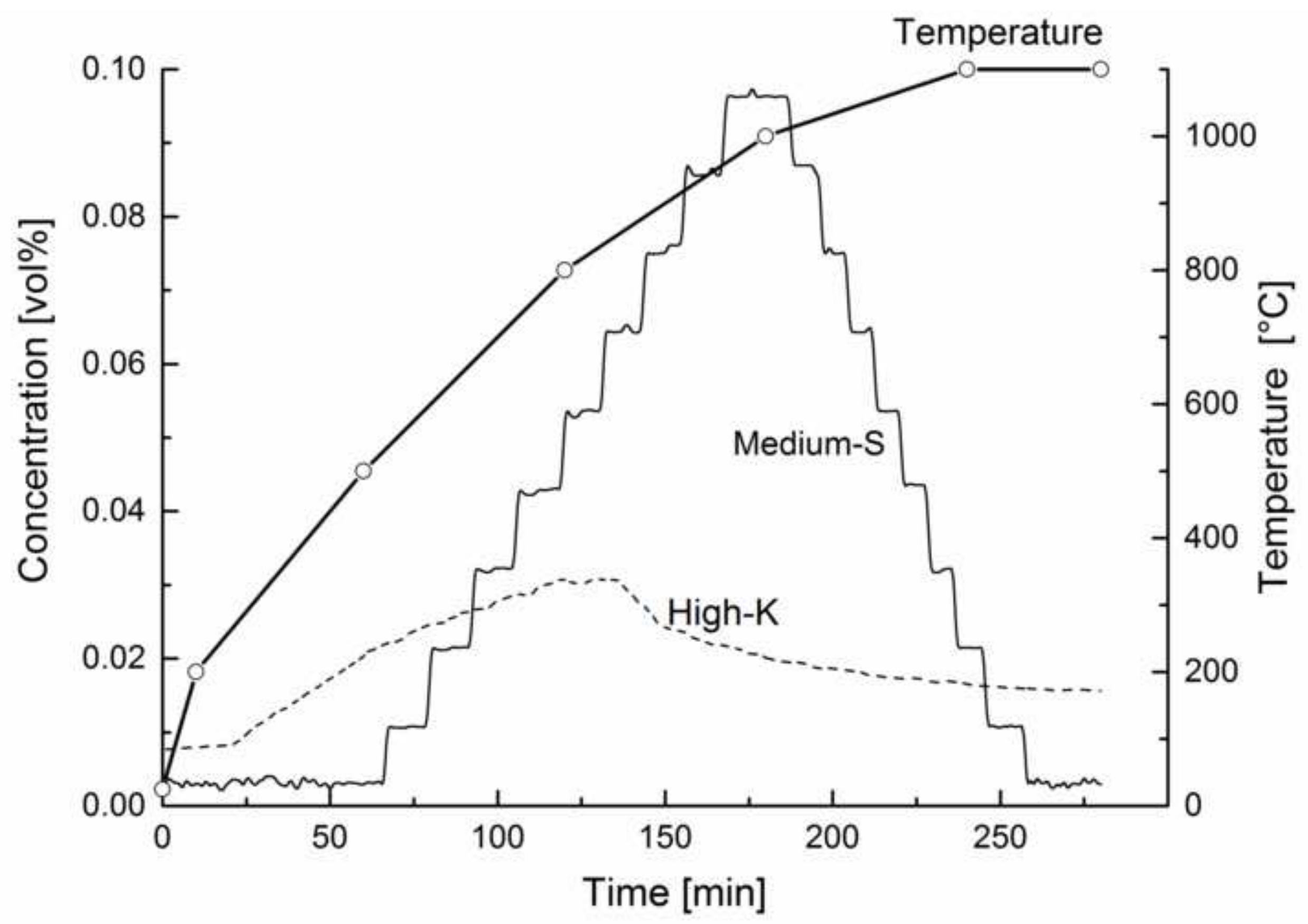




\section{Compression}

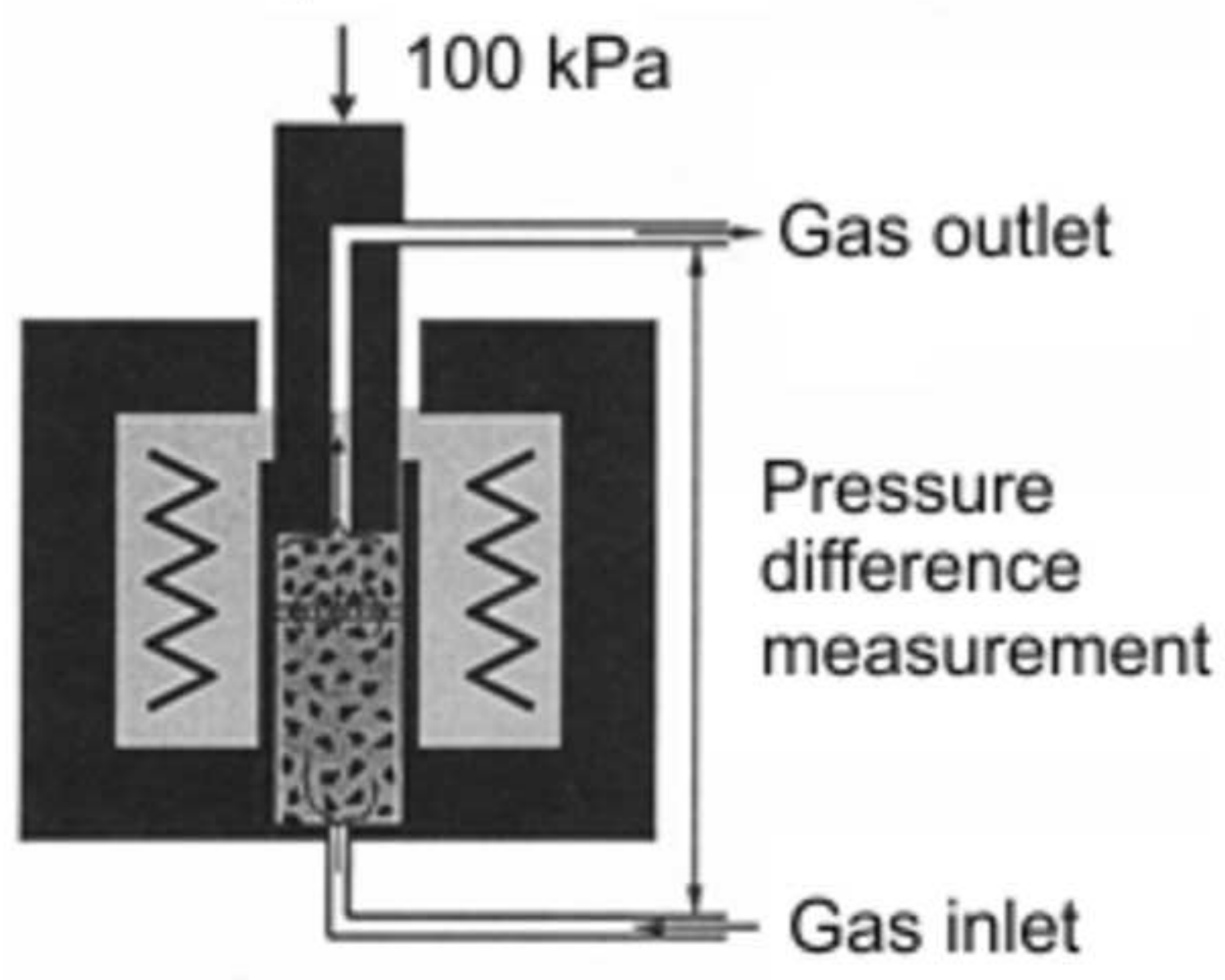




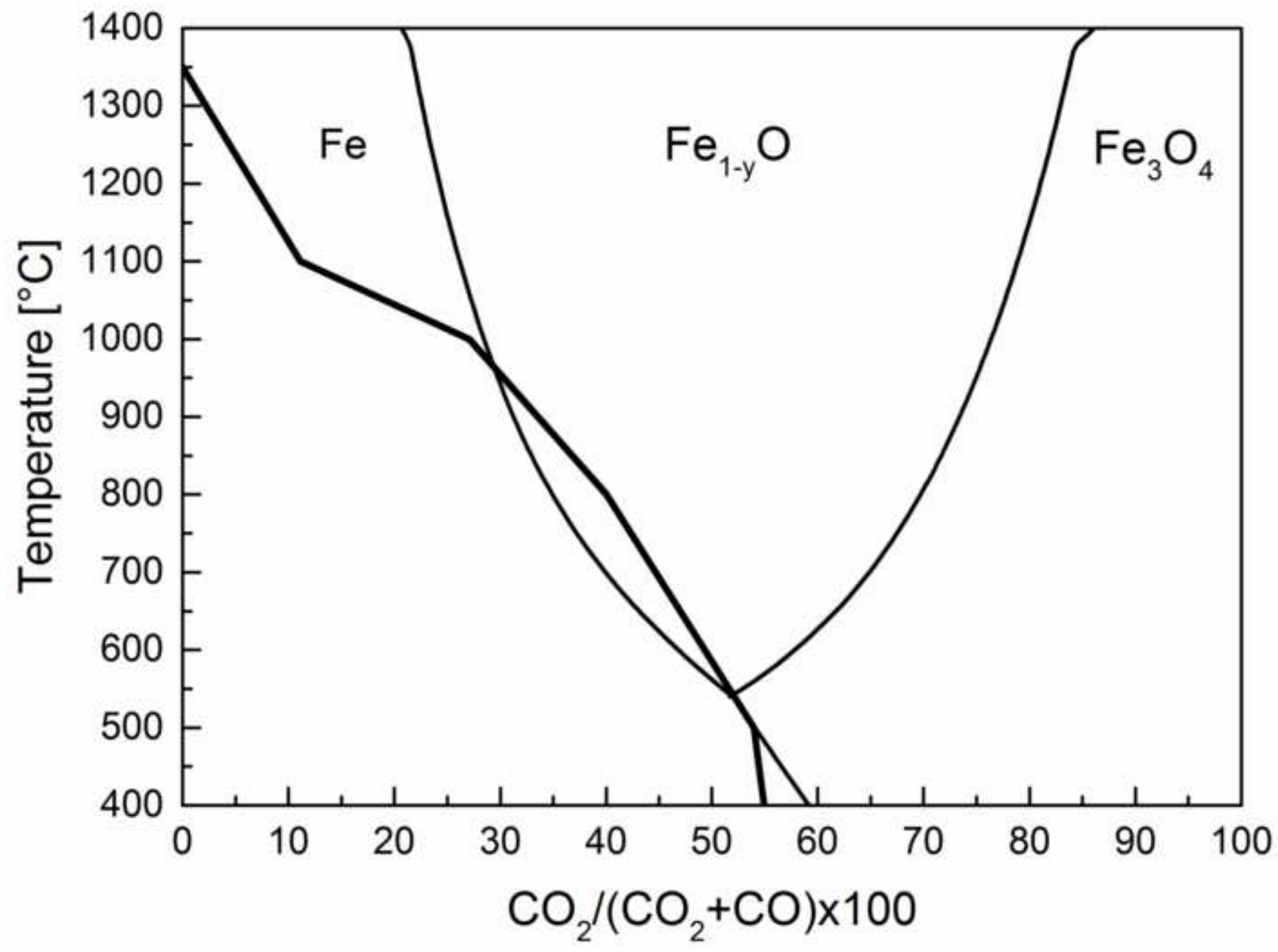


Test piece after the reduction-softening test

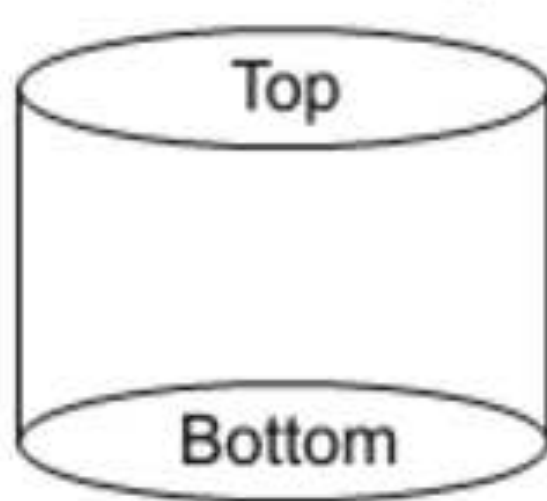

Cutting

Photography Polished samples

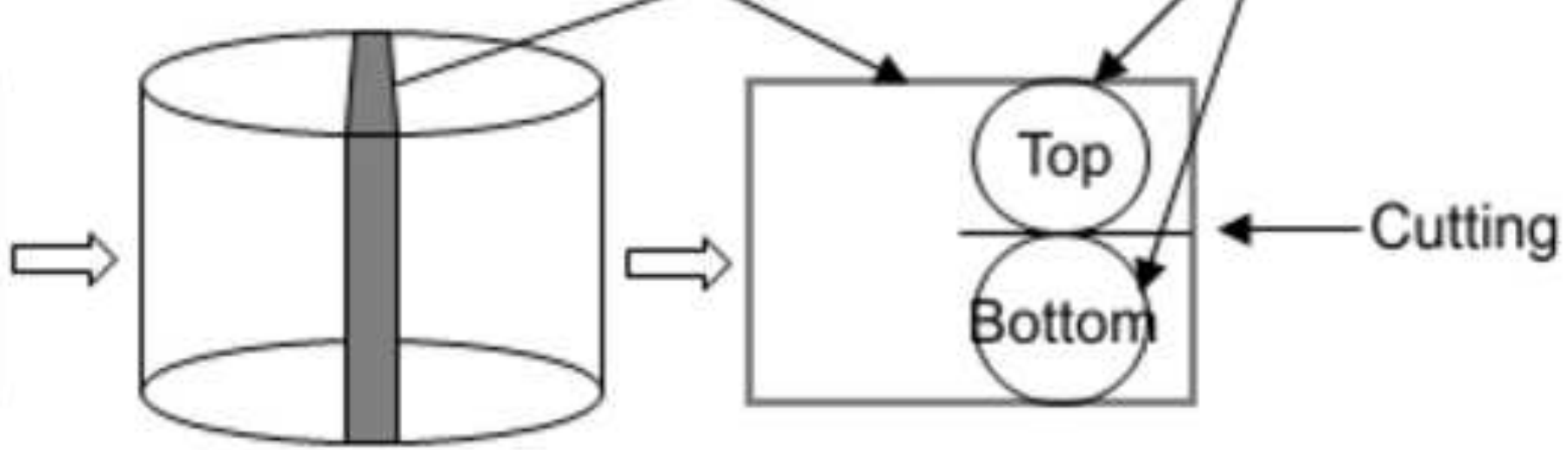


Click here to download high resolution image

Non-fluxed
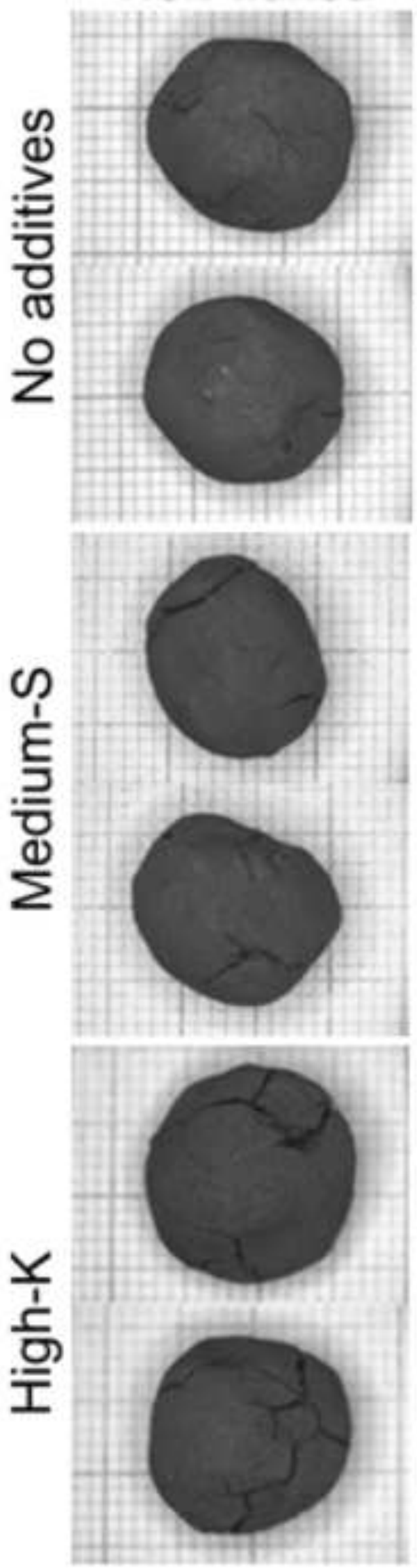

Fluxed
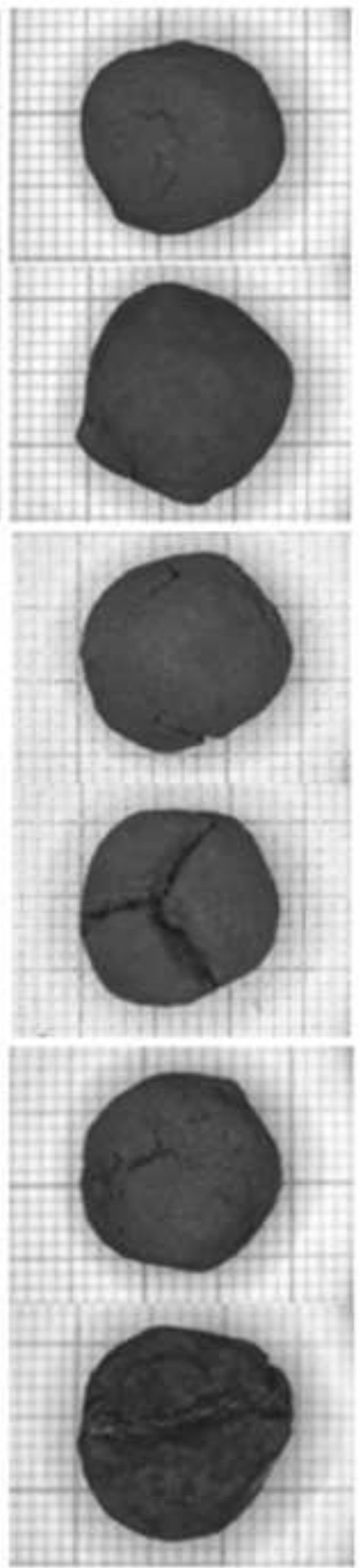


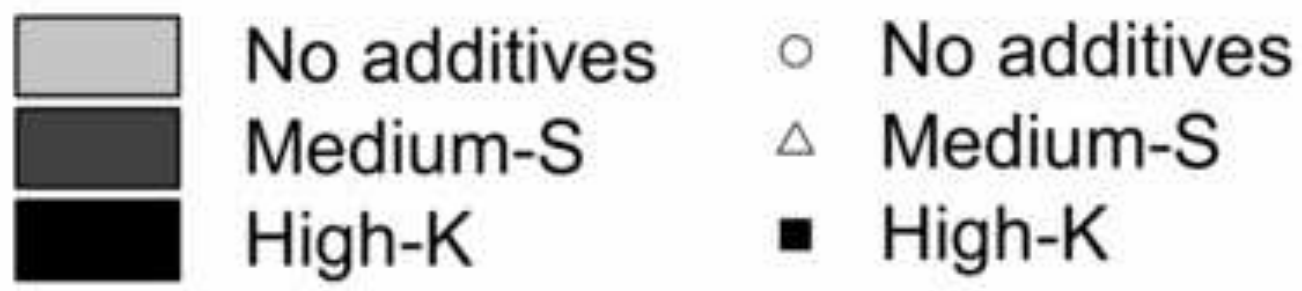
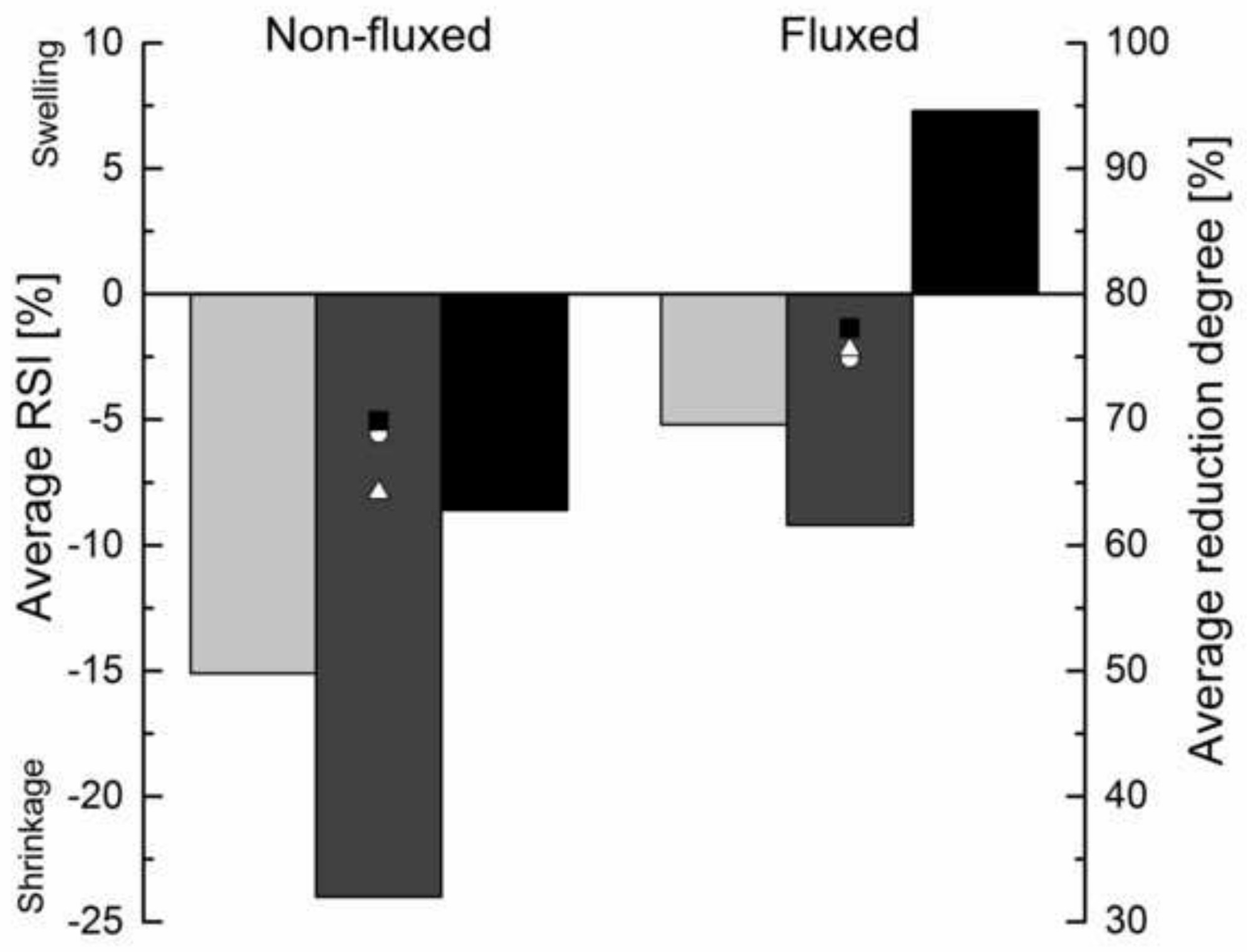


\section{Non-fluxed} TOP

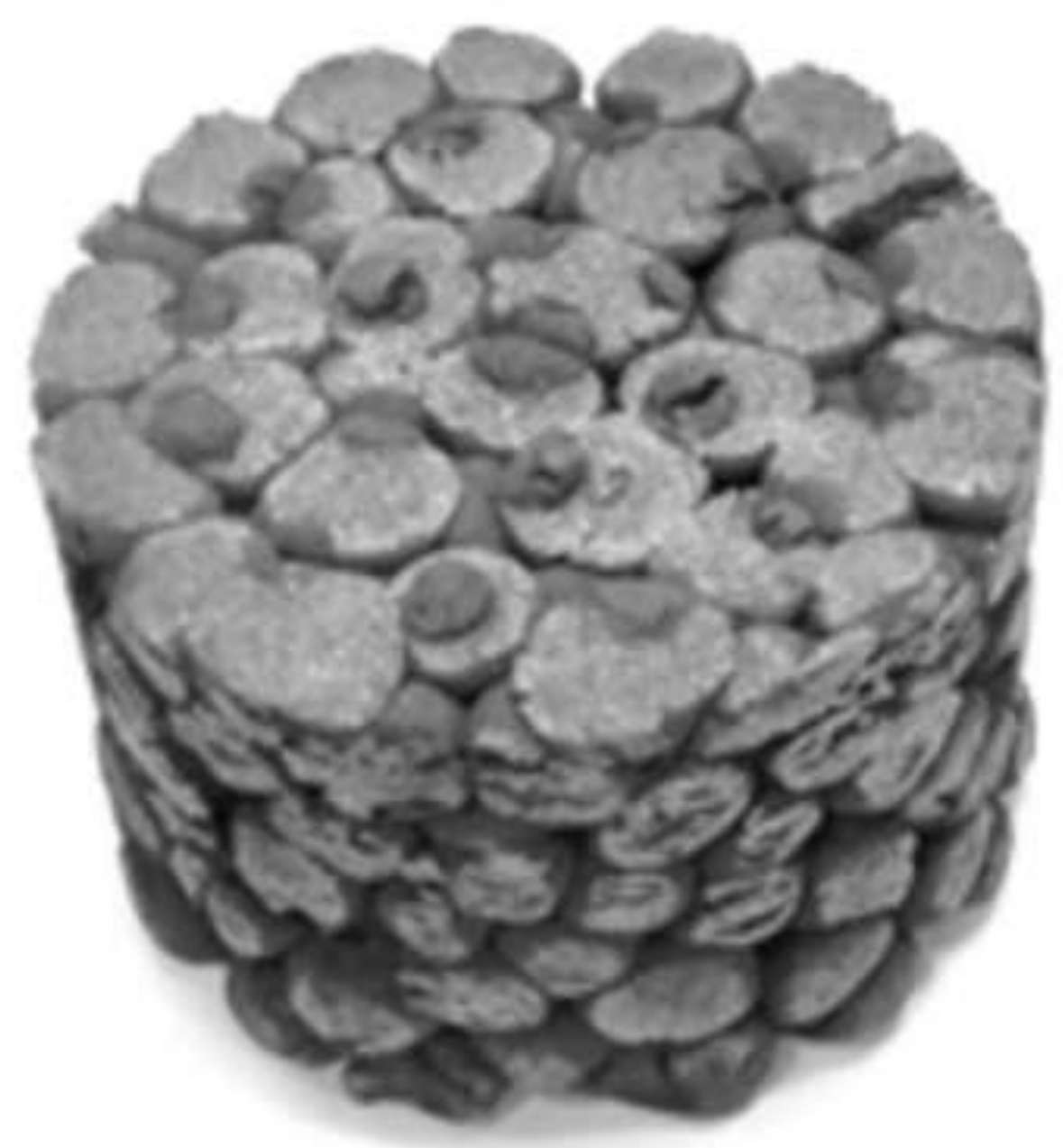

BOTTOM

\section{Fluxed} TOP

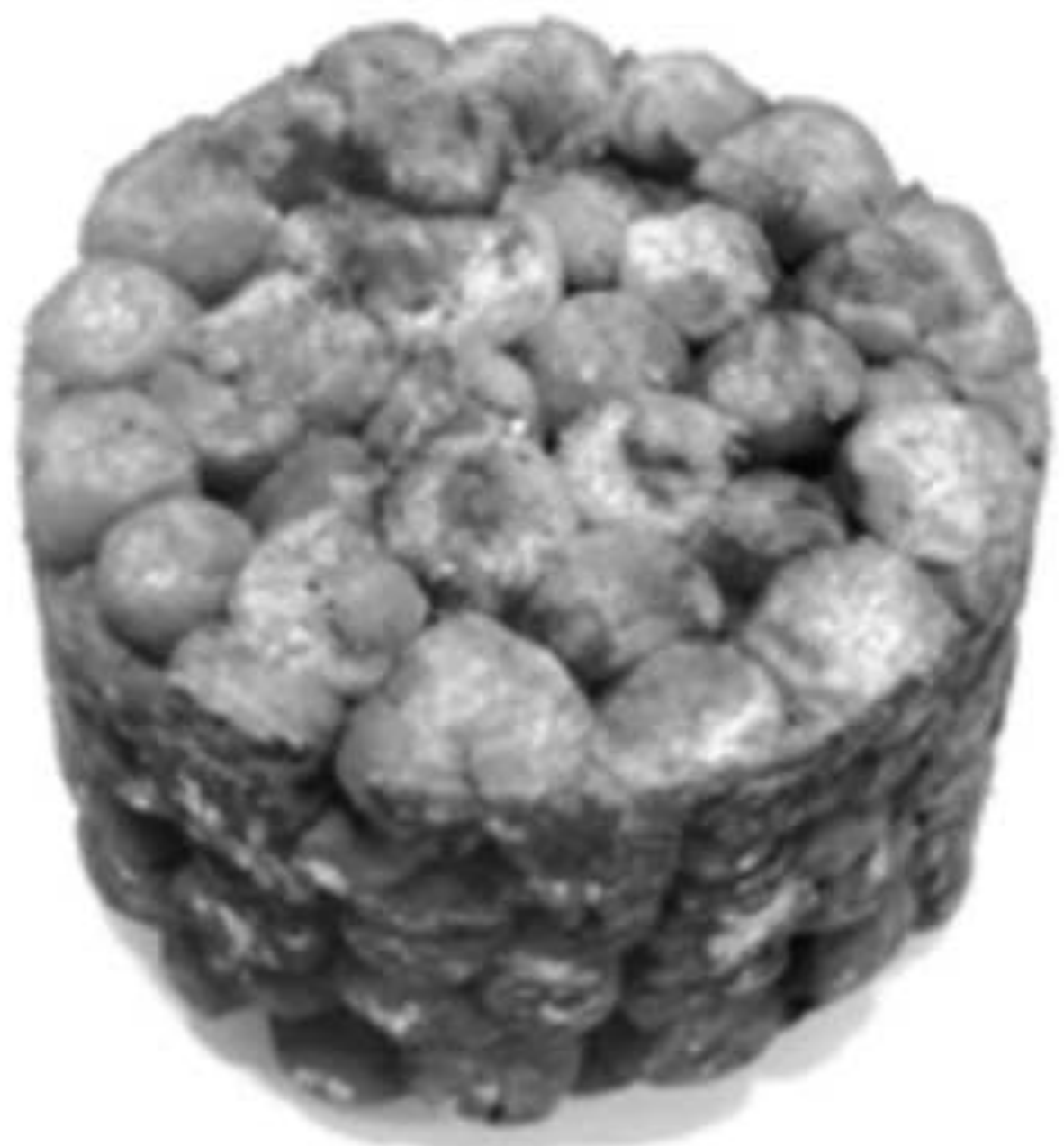

BOTTOM 


\section{Non-fluxed}

TOP

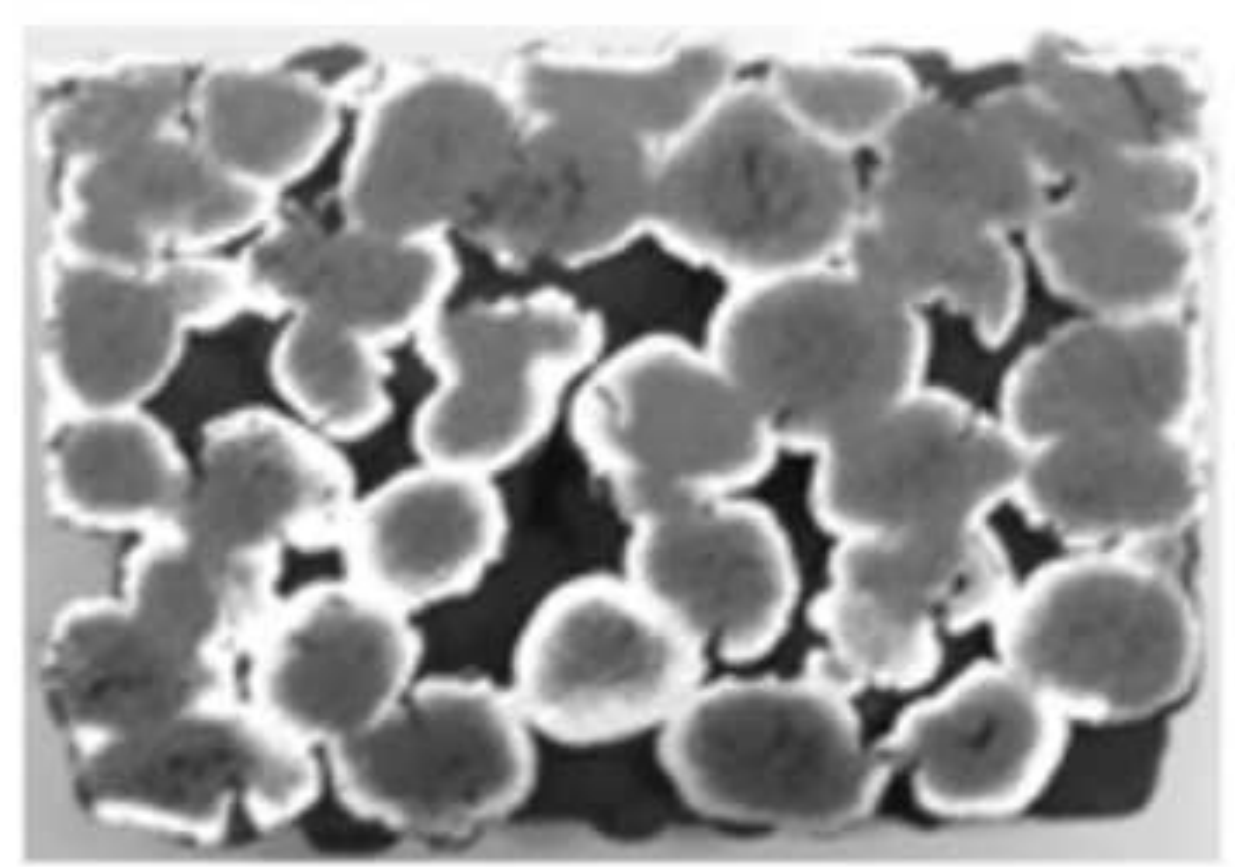

BOTTOM

\section{Fluxed}

\section{TOP}

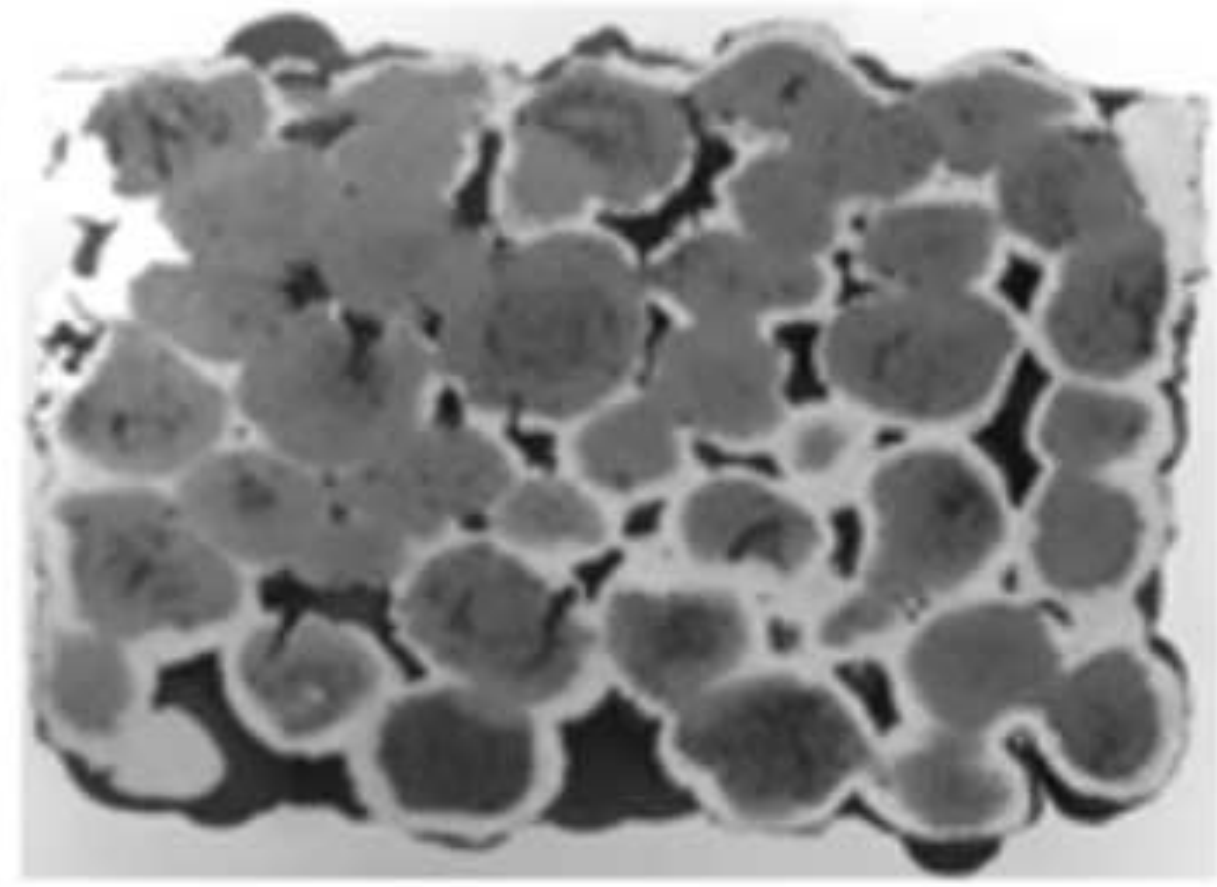

\section{BOTTOM}




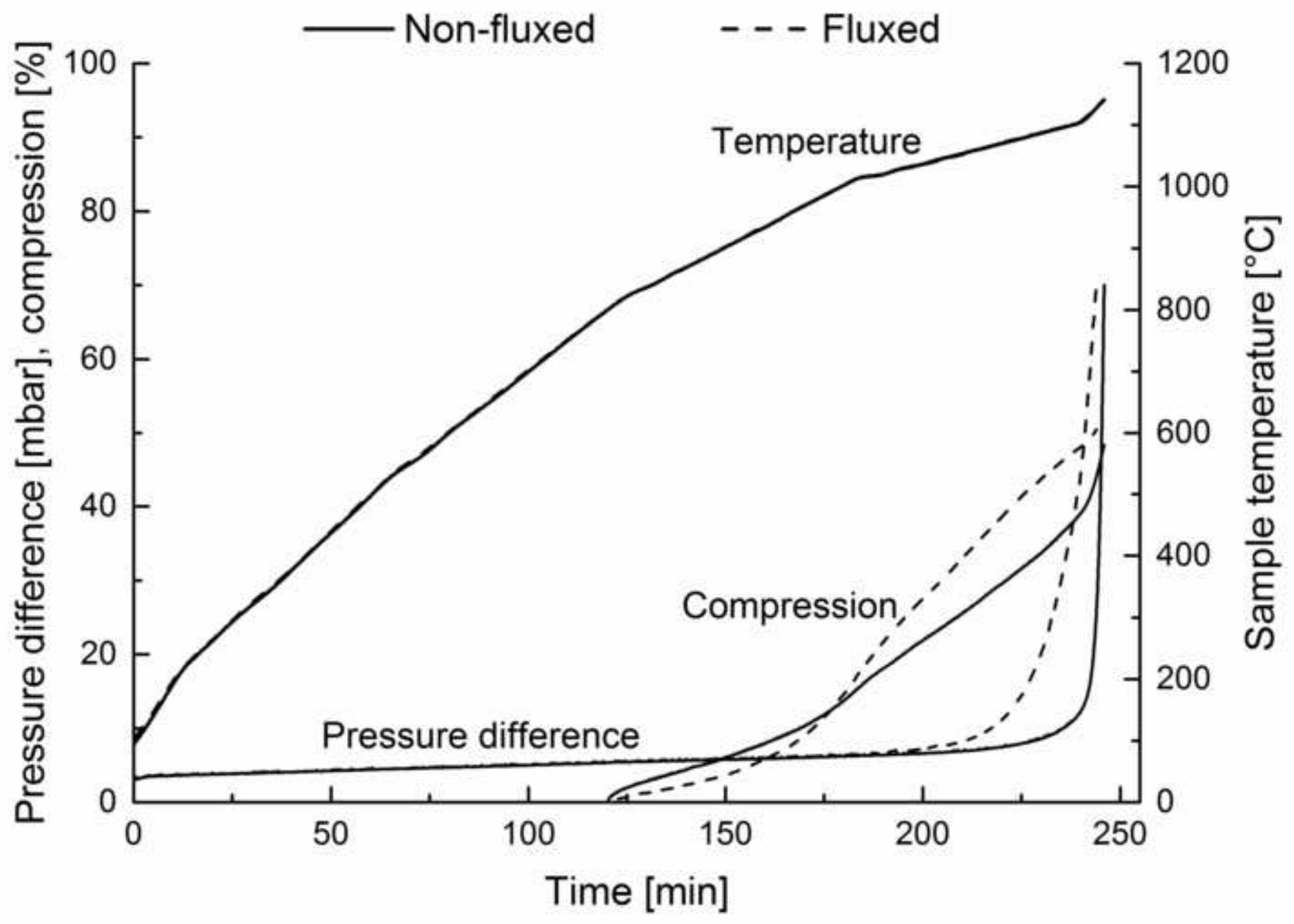


$\longrightarrow$ Non-fluxed $\quad-\circ$-Fluxed

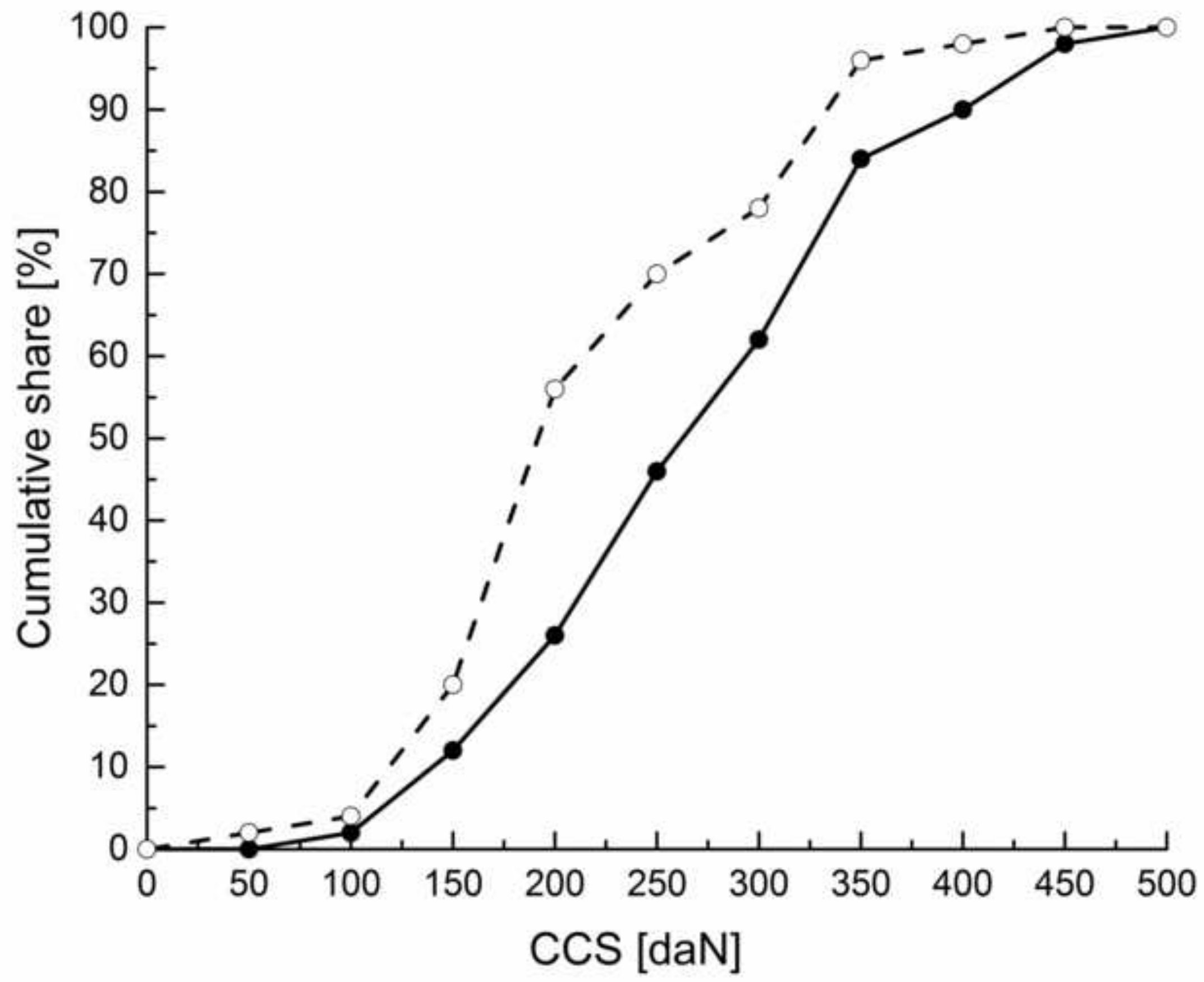


Click here to download high resolution image

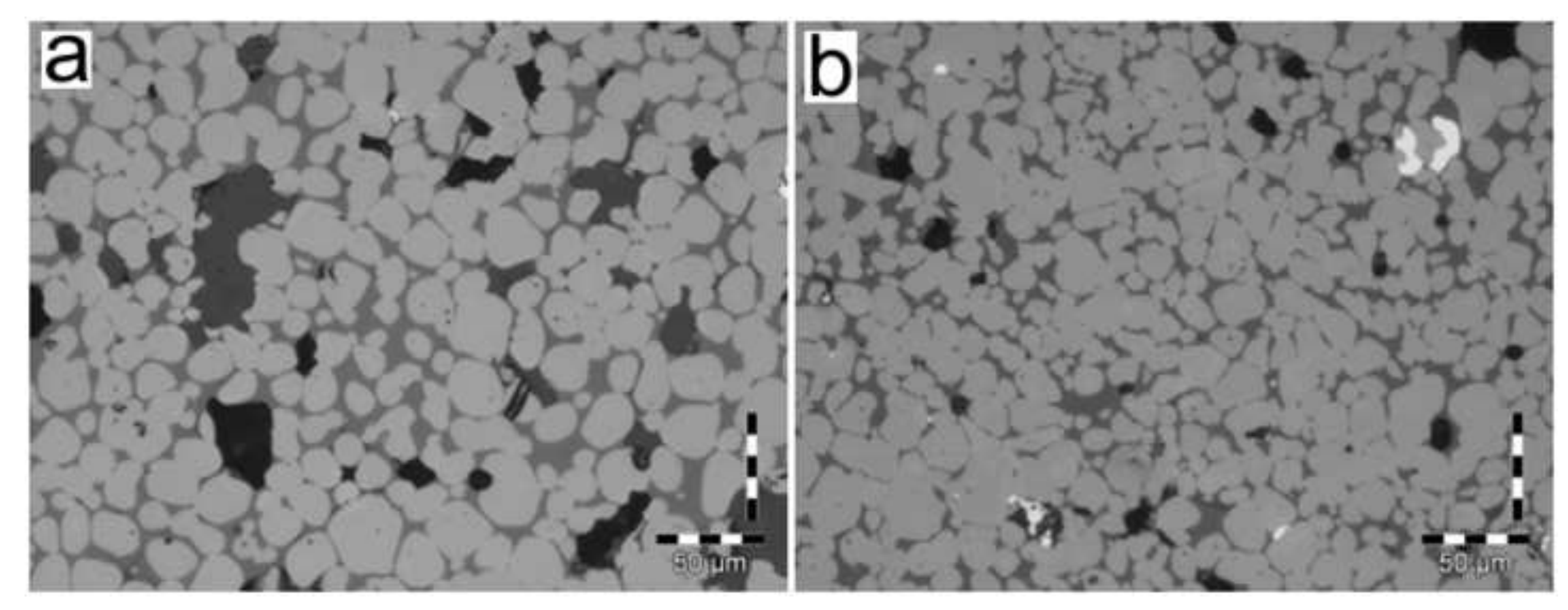


Click here to download high resolution image
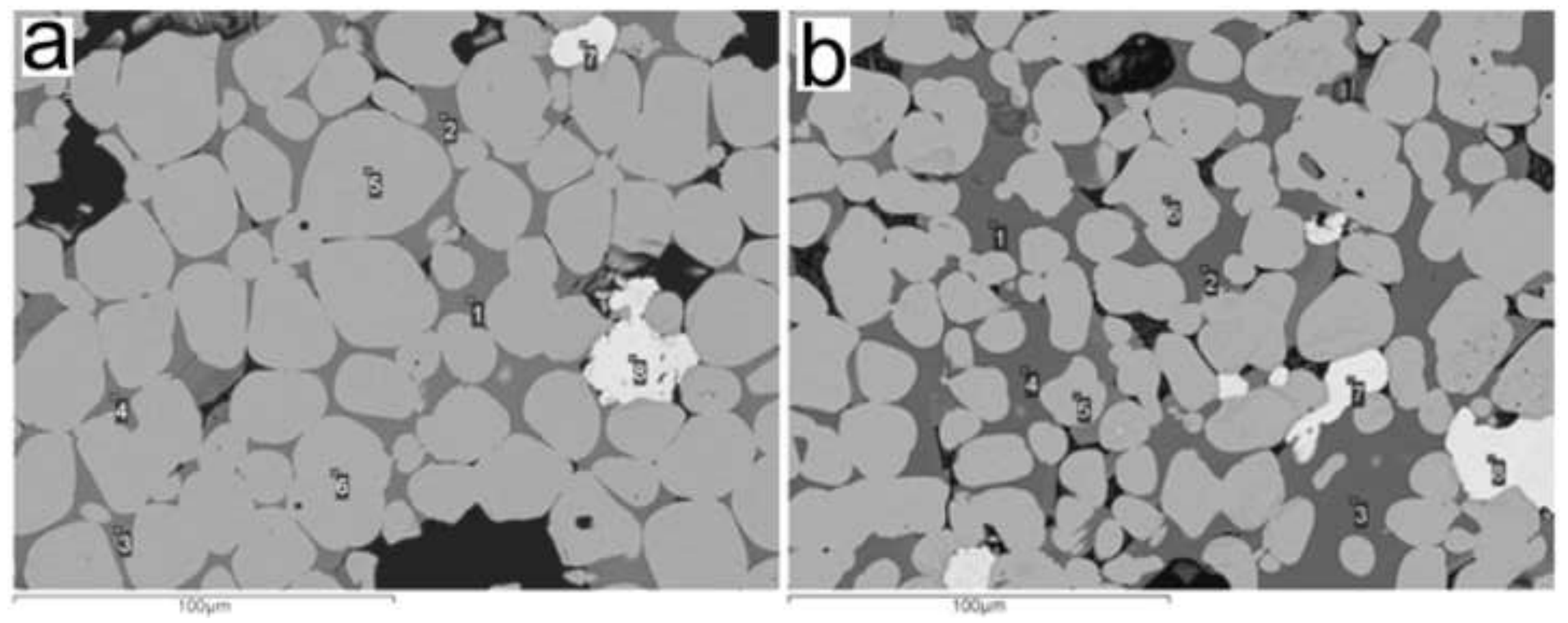


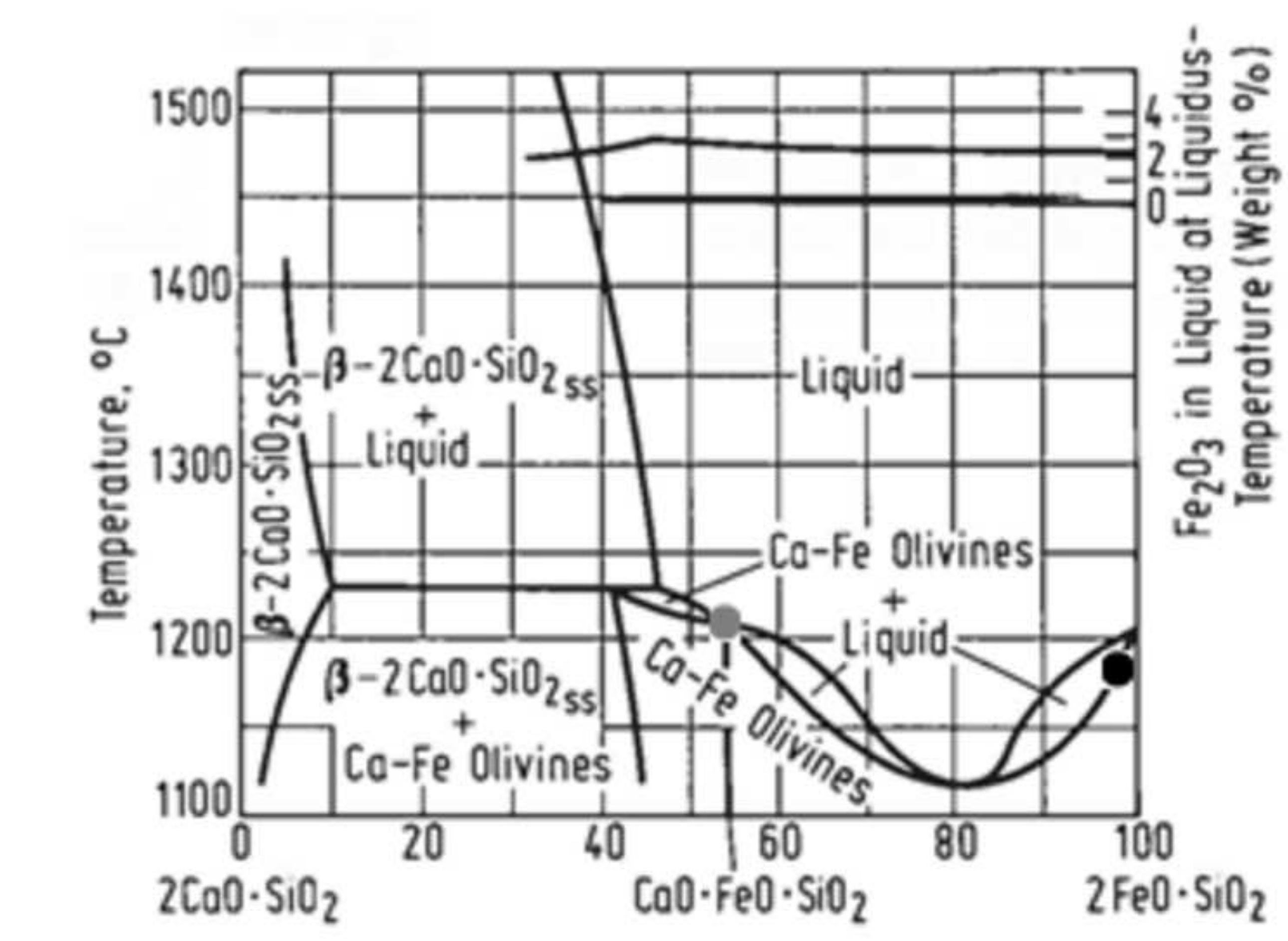$$
\text { . }
$$ 